\title{
Review Article \\ Regulation of Metabolic Disease-Associated Inflammation by Nutrient Sensors
}

\author{
Alex S. Yamashita, ${ }^{1}$ Thiago Belchior, ${ }^{1}$ Fábio S. Lira, ${ }^{2}$ Nicolette C. Bishop ${ }^{(D)}{ }^{3}$ \\ Barbara Wessner, ${ }^{4}$ José C. Rosa $(1),{ }^{5}$ and William T. Festuccia $\left(\mathbb{1}{ }^{1}\right.$ \\ ${ }^{1}$ Department of Physiology and Biophysics, Institute of Biomedical Sciences, University of Sao Paulo, 05508000 Sao Paulo-SP, Brazil \\ ${ }^{2}$ Exercise and Immunometabolism Research Group, Department of Physical Education, Universidade Estadual Paulista (UNESP), \\ 19060-900 Presidente Prudente-SP, Brazil \\ ${ }^{3}$ School of Sports, Exercise and Health Science, Loughborough University, Loughborough, UK \\ ${ }^{4}$ Centre for Sport Science and University Sports, Vienna, Austria \\ ${ }^{5}$ Department of Cell Biology and Development, Institute of Biomedical Sciences, University of Sao Paulo, \\ 05508000 Sao Paulo-SP, Brazil
}

Correspondence should be addressed to William T. Festuccia; william.festuccia@gmail.com

Received 28 March 2018; Revised 21 May 2018; Accepted 14 June 2018; Published 4 July 2018

Academic Editor: Tânia Silvia Fröde

Copyright (C) 2018 Alex S. Yamashita et al. This is an open access article distributed under the Creative Commons Attribution License, which permits unrestricted use, distribution, and reproduction in any medium, provided the original work is properly cited.

\begin{abstract}
Visceral obesity is frequently associated with the development of type 2 diabetes (T2D), a highly prevalent chronic disease that features insulin resistance and pancreatic $\beta$-cell dysfunction as important hallmarks. Recent evidence indicates that the chronic, low-grade inflammation commonly associated with visceral obesity plays a major role connecting the excessive visceral fat deposition with the development of insulin resistance and pancreatic $\beta$-cell dysfunction. Herein, we review the mechanisms by which nutrients modulate obesity-associated inflammation.
\end{abstract}

\section{Introduction}

Visceral obesity, the excessive accumulation of fat in the adipose depots located inside the peritoneal cavity, is a major risk factor for the development of several highly prevalent, chronic diseases, namely, type 2 diabetes (T2D), cardiovascular diseases, and some types of cancer, among others $[1,2]$. The increased prevalence of visceral obesity in the last decades has dramatically raised the incidence of its associated diseases. It was estimated, for example, that approximately 415 million people aged $20-79$ years in the world had diabetes, such numbers that are expected to grow to 642 million in 2040 [3]. Importantly, a large portion of either overweight or obese individuals also present with $\mathrm{T} 2 \mathrm{D}$, supporting the strong association between both diseases [4].

T2D is a heterogeneous disease that features insulin resistance and pancreatic $\beta$-cell dysfunction as major hallmarks. Insulin resistance is defined as the inability of insulin to properly stimulate glucose uptake in skeletal muscle and adipose tissue and to inhibit hepatic glucose production. Despite of the intense research in this area, there are still some doubts about the exact sequence of events that leads to the development of obesity-associated insulin resistance as elegantly reviewed in [5]. The most traditional hypothesis suggests that either obesity or the intake of obesogenic, hypercaloric diet promotes first insulin resistance, which then results in hyperglycemia followed by hyperinsulinemia. In accordance to this hypothesis, hyperglycemia and a compensatory hyperinsulinemia are major metabolic phenotypes found in the early stages of T2D. Chronically, hyperglycemia may promote, in a more advanced stage of T2D, pancreatic islet damage and a subsequent decline in insulin secretion. Interestingly, recent studies have suggested, based on findings obtained in obese humans and rodents and patients after bariatric surgery, that hyperinsulinemia, instead of hyperglycemia, is the primary event involved in the development of insulin 
resistance and T2D. In accordance with this hypothesis, either obesity or the intake of an obesogenic, hypercaloric diet enhances $\beta$-cell insulin secretion and/or reduces its degradation, promoting hyperinsulinemia, which chronically results in insulin resistance and therefore hyperglycemia. Taking into account the strong evidence supporting both of the aforementioned hypotheses, one may argue that the exact sequence of events involved in the development of obesityassociated insulin resistance and $\mathrm{T} 2 \mathrm{D}$ may vary according to the underlying obesogenic conditions.

T2D results from a complex interaction between genetic and environmental factors. Studies evaluating familial risks indicate that T2D has a high 50\% heritability, in which individuals with either one affected first-degree relative or at least two affected siblings, independently of the parental diabetes status, are at the higher risk of developing T2D [1]. Genome-wide association studies have identified so far more than 40 diabetes-associated loci, which are related to $\beta$-cell function, insulin sensitivity, and obesity and respond to approximately $10 \%$ of T2D heritability [1]. Noteworthily, the greatest majority of T2D cases are associated with two or more genetic mutations (polygenic nature), such alterations that in most cases increase the propensity, but are not sufficient to induce disease development without the contribution of environmental and/or behavioral factors. The very same rationale applies to the development of visceral obesity, a major risk factor for T2D [2].

Inflammation is at the very centre of metabolic diseases such as obesity, T2D, and metabolic syndrome, playing an important role not only in their development but also as a linking factor between them. Indeed, visceral obesity is associated with a chronic inflammatory process of low intensity, defined as metabolic inflammation or "metainflammation" that affects important metabolic tissues such as adipose tissue, liver, skeletal muscle, pancreas, intestines, and hypothalamus, among others [6]. The adipose tissue, for example, the organ that defines obesity, develops upon this condition an inflammatory process characterized by the recruitment, infiltration, and polarization of leukocytes to a proinflammatory profile [6]. Among the leukocytes recruited to adipose tissue upon obesity are neutrophils, macrophages, dendritic and mast cells from the innate immune system, and several subtypes of $\mathrm{T}$ and $\mathrm{B}$ lymphocytes from the adaptive immune system [7]. Several stimuli were suggested to mediate the induction of leukocyte recruitment to adipose tissue found upon obesity such as the following: (1) activation of adipocyte proinflammatory pathways by LPS and saturated fatty acids and secretion of chemokines such as monocyte chemoattractant protein-1 (MCP-1), (2) tissue hypoxia, (3) adipocyte death, and (4) mechanical stress between adipocytes and the extracellular matrix [6]. Importantly, after recruitment, tissue leukocytes also undergo polarization to different phenotypes. Macrophages, for example, which account for approximately $50 \%$ of the cells composing adipose tissue upon obesity, undergo during this condition a polarization to a proinflammatory M1 phenotype [8]. These proinflammatory leukocytes along with activated, hypertrophied adipocytes secrete a plethora of proinflammatory cytokines/adipokines, chemokines, and lipids, perpetuating inflammation and impairing tissue metabolism. Importantly, proinflammatory mediators have been shown to induce insulin resistance by impairing several steps in the intracellular signaling cascade of this hormone $[9,10]$ and adipose tissue macrophage depletion attenuates diet-induced obesity, inflammation, and insulin resistance [8].

Intake of excessive amounts of nutrients is a major underlying cause of obesity and obesity-associated complications and an important modulator of many phenotypes associated with this condition including inflammation. We review herein the mechanisms by which excessive intake of nutrients chronically modulates visceral obesity-associated inflammation with a special emphasis in the role of nutrient sensors as likely mediators of these actions.

1.1. Nutrient Sensing. Nutrients have vital functions in cells acting not only as metabolic substrates for energy production but also as building blocks for the synthesis of macromolecules and cellular components [11]. In the face of such essential roles of nutrients, organisms have evolved several mechanisms to sense levels of specific nutrients in the extra- and intracellular compartments allowing the proper coordination of rates of growth, proliferation, and function according to nutrient availability [11]. Nutrient-sensing mechanisms are found in all organisms; some of them are well conserved through evolution being found in eukaryotic organisms varying from yeast to mammals, whereas others are exclusive of prokaryotes [11]. Importantly, in multicellular organisms, some nutrient sensing mechanisms also evolved to undergo regulation by the endocrine system, allowing the coordination at whole-body level of nutrient sensing activity among different cells/tissues, which is of major importance in the maintenance of wholebody homeostasis.

Proteins that have the capacity to sense fluctuations in the concentration of a specific nutrient or a product of its metabolism within the physiological range are denominated as nutrient sensors [11]. Nutrient sensors, which can be located at different cell compartments as the plasma membrane, cytosol, organelle endomembranes, or the nucleus, respond to fluctuations in nutrient levels through diverse mechanisms varying from the activation of phosphorylation cascades, changes in gene transcription, and enzymatic activities, among others. Upon obesity, nutrient sensors are chronically challenged by excessive amounts of some nutrients, which impact their activity and regulatory role over cellular processes. More specifically, metabolomics studies have found that visceral obesity is frequently associated with increased serum concentrations of glucose, branched-chain and aromatic amino acids (BCAA and AA, resp.), and several lipids such as saturated and omega 6 fatty acids, acylcarnitines, and phospholipids, among others [12]. Chronic tissue exposure to excessive amounts of some of these nutrients has been implicated in the development of common features of obesity and T2D such as organelle dysfunction (endoplasmic reticulum and mitochondria stress) and oxidative stress, both of which being candidates as triggering factors of obesity-associated inflammation and insulin resistance. On the other hand, elevated intake of some nutrients such as 
$\omega-3$ polyunsaturated fatty acids was shown to protect from obesity-associated inflammation and insulin resistance.

1.2. Insulin Signaling and Inflammation. Insulin is a major anabolic hormone that exerts its actions by interacting with a receptor constituted of two extracellular $\alpha$-chains containing the ligand-binding site and two transmembrane $\beta$-chains that possess the tyrosine kinase activity. The insulin receptor (IR) displays 50\% homology to the insulin-like growth factor receptor (IGFR), and in some cells, both receptors may form IR-IGFR hybrids that recognize both insulin and IGF-1 as ligands $[13,14]$. Upon interaction with insulin or IGF-1, the receptor changes its conformation and phosphorylates at tyrosine residues itself and a family of adaptor proteins known as insulin receptor substrates (IRS). Tyrosinephosphorylated IRS then binds to the SH2 domain of the p85 regulatory subunit of the lipid kinase phosphoinositide3-kinase (PI3K) promoting the conversion of the membrane lipid phosphatidylinositol 3,4-biphosphate (PIP2) to phosphatidylinositol 3,4,5-biphosphate (PIP3). PIP3 then binds to and recruits protein kinase B/Akt to the cell membrane promoting its phosphorylation at Ser473 and Thr308 by the mechanistic target of rapamycin complex 2 (mTORC2) and phosphoinositide dependent-kinase 1 (PDK1), respectively [15]. Upon its phosphorylation and activation, Akt promotes glucose uptake by phosphorylating Rab GAP TBC1D4 (AS160) inducing therefore the translocation of vesiclecontaining glucose transporter 4 (GLUT4) to the plasma membrane [16] and inhibits hepatic gluconeogenesis by phosphorylating and inactivating the transcription factor forkhead box protein O1 (FoxO1) and the CREB-CBPCRTC2 complex, thus suppressing the expression of gluconeogenic enzymes phosphoenolpyruvate carboxykinase (PEPCK) and glucose 6-phosphatase (G6Pase) [15, 17]. In addition to those actions that are susceptible to developing resistance upon obesity and $\mathrm{T} 2 \mathrm{D}$, insulin, through the sequential PI3K-Akt activation, inhibitory phosphorylation of the complex tuberous sclerosis complex 1/2 (TSC1/ TSC2), and activation of Ras homolog enriched in the brain (Rheb), activates the mechanistic target of rapamycin complex 1 (mTORC1), which in turn promotes protein synthesis by phosphorylating the ribosomal protein S6K and eukaryotic translational initiation factor 4E-binding protein 1 (4E-BP), among many other processes [18]. Another important signaling pathway induced by insulin is the mitogen-activated protein kinase (MAPK), reviewed in detail elsewhere [19], which promotes cell proliferation, among other actions.

In healthy cells, intracellular insulin signaling is constantly monitored by several regulatory checkpoints that, through a complex system of negative feedback loops, keeps the level of activity of this signaling pathway within the optimal physiological range. One of these regulatory loops is exerted by mTORC1 downstream substrate S6K1 that, when phosphorylated and activated, catalyzes a negative feedback characterized by the inhibitory phosphorylation of IRS at serine residues, blocking its ability to interact and allosterically activate PI3K [20]. Another feedback loop modulating insulin signaling catalyzed by mTORC1 involves the phosphorylation and stabilization of the adaptor protein GRB10, which binds via SH2 domain to the phosphorylated tyrosine at the insulin receptor blocking the interaction with IRS $[21,22]$. In addition, GRB10 may also reduce insulin signaling by promoting IRS ubiquitination via the ubiquitin ligase E2 NEDD4.2 and proteasomal degradation [23]. Importantly, dysfunction of these regulatory systems and feedback loops promotes chronic overactivation of intracellular insulin signaling and is associated with cancer incidence, whereas the opposite, that is, impaired insulin signaling (resistance), defines T2D.

The mechanisms by which cells become refractory to insulin action in obesity are not completely understood. Compelling evidence published in the early 1990s had shed light on this issue not only by establishing obesity as an inflammatory disease but also by indicating that inflammatory mediators may play a key role as linking factors between excessive fat deposition and the development of insulin resistance and other associated diseases [24]. More specifically, it was shown in these studies that the proinflammatory cytokine tumor necrosis factor- (TNF-) $\alpha$ is oversecreted by adipose tissue in obesity, promotes insulin resistance in rodents, and correlates with insulin resistance in obese children and adults [24-27]. Furthermore, it was later shown that deletion of TNF- $\alpha$ or its receptor protects mice against diet-induced obesity and insulin resistance [28], whereas TNF- $\alpha$ blockade by treatment with its monoclonal antibody infliximab improved glucose homeostasis in patients with rheumatic disease [29-32]. In spite of those promising findings, TNF$\alpha$ blockade was not effective in treating insulin resistance in obese patients [33], such findings that were somehow expected considering that inflammation is a complex process characterized by the involvement of many protein and lipid mediators. Indeed, subsequent studies have shown that other proinflammatory mediators such as interleukin- (IL-) $1 \beta$, IL6 , interferon- (IFN-) $\gamma$, ceramides, prostaglandins, and lipopolysaccharide (LPS) from the membrane of gram-negative bacteria residing in gut microbiota, among others, are also involved in the development of obesity-associated insulin resistance [34-36]. Among those, obesity-associated elevation in the circulating levels of LPS, defined as metabolic endotoxemia, has been considered as a major triggering factor that links excessive intake of fat and the development of obesity-associated inflammation [35, 37]. Another important inflammatory mediator involved in obesity is IL- $1 \beta$, a cytokine whose secretion requires its processing by caspase- 1 as the result of the activation of the nucleotide-binding domain, leucine-rich-containing family, pyrin domain-containing 3 (NLRP3) inflammasome, a multimeric cytosolic protein complex activated by pathogen-associated molecular pattern (PAMP) and danger-associated molecular pattern (DAMP) molecules [38]. Indeed, blockade of IL- $1 \beta$ actions by treatment with a receptor antagonist (anakinra) or monoclonal antibody reduces systemic inflammation and improves glycemia and $\beta$-cell secretory function in T2D patients [34].

One common signaling event that is at the very centre of obesity-associated inflammation is the activation of nuclear factor $\kappa$-light-chain-enhancer of activated $\mathrm{B}$ cells $(\mathrm{NF} \kappa \mathrm{B})$, a conserved family of transcription factors that regulate 
inflammatory processes, immune function, development, and growth [39]. Importantly, chronic $\mathrm{NF} \kappa \mathrm{B}$ activation may be involved in the development of several diseases in addition to obesity such as T2D and cancer, among others. Five $\mathrm{NF} \kappa \mathrm{B}$ protein members are expressed in mammalian

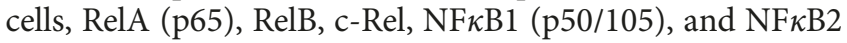
(p52/100) [39]. In the absence of stimulus, dimers of NF $\kappa B$ protein members are bound to the inhibitor $\kappa \mathrm{B}(\mathrm{I} \kappa \mathrm{B})$, which maintains the $\mathrm{NF} \kappa \mathrm{B}$ complex in the cytosol, inhibiting therefore its translocation to the nucleus and transcriptional activity. Proinflammatory mediators activate $\mathrm{NF} \kappa \mathrm{B}$ through a series of events that involve $\mathrm{I} \kappa \mathrm{B}$ phosphorylation by $\mathrm{I} \kappa \mathrm{B}$ kinase (IKK), followed by its ubiquitination and proteasomal degradation, which then release the p50/RelA (p65) dimer for translocation to the nucleus, where it can repress or induce gene transcription by binding to 9-10 nucleotide sequences in DNA promoter regions denominated as $\mathrm{NF} \kappa \mathrm{B}$ response elements [39].

Proinflammatory mediators through the activation of several signaling pathways such as the canonical toll-like receptor- (TLR-) IKK-NF $\kappa \mathrm{B}$, and the kinases c-Jun Nterminal kinases (JNK), Janus kinase (JAK), and mTOR, among others [10], promote insulin resistance by impairing different steps in the intracellular insulin signaling cascade, namely, by either phosphorylating IRS at inhibitory serine residues, or inhibiting Akt dual phosphorylation and activation, or reducing AS160 phosphorylation and GLUT-4 translocation $[9,10,40]$. Importantly, resistance selectively affects only few processes regulated by insulin such as glucose uptake in myocytes and adipocytes and glucose production in hepatocytes. Other insulin actions such as the activation of protein synthesis and de novo lipogenesis do not seem to be impaired in insulin-resistant conditions [40-42]. Below, we review the molecular mechanisms by which some nutrients modulate obesity-associated inflammation.

1.3. Glucose Excess (Glucotoxicity) and Inflammation. Chronic tissue exposure to hyperglycemia, due to the elevated intake of diets rich in simple carbohydrates of high glycemic index and/or impaired glucose homeostasis, is associated with the development of tissue inflammation. It has been extensively shown, for example, in rodent adipose tissue, liver, and pancreas, that high sucrose feeding promotes an inflammatory process characterized by enhanced leukocyte recruitment and polarization to a proinflammatory phenotype, as well as exacerbated cytokine production and secretion [43-47]. Similarly to rodents, acute and persistent hyperglycemia in humans is associated with elevated circulating levels of several proinflammatory cytokines and markers of endothelial and oxidative stress $[48,49]$. Furthermore, human and rodent pancreatic $\beta$-cells exposed to high glucose levels displayed NLRP3 inflammasome and caspase- 1 activation and enhanced IL- $1 \beta$ production [50]. The underlying mechanisms by which exposure to high glucose levels activates the NLRP3 inflammasome and whether this occurs in other cell types than $\beta$-cells are unknown and deserve to be investigated. Recent findings stating that mitochondrial dissociation and inhibition of the rate-limiting enzyme of glycolysis hexokinase promote

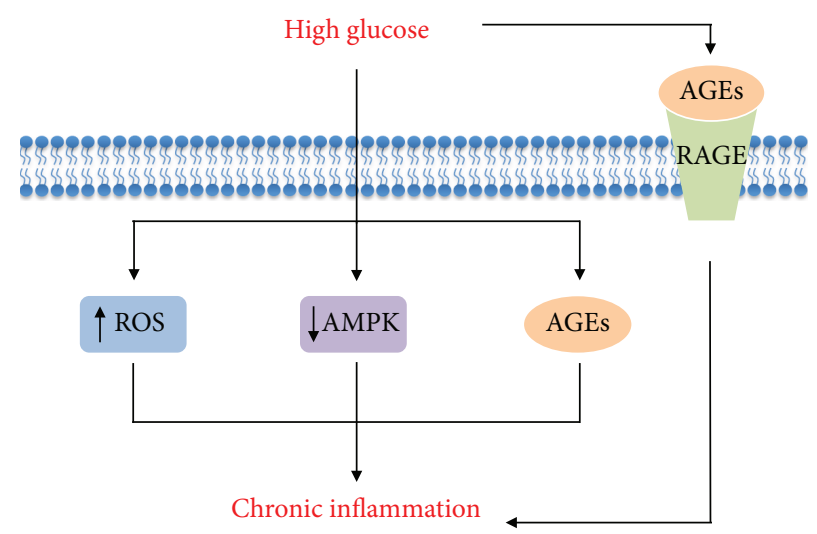

FIgURe 1: Main mechanisms by which glucose excess induces chronic inflammation. AGEs: advanced glycation end products; AMPK: AMP-activated protein kinase; RAGE: receptor for AGEs; ROS: reactive oxygen species.

NLRP3-inflammasome activation and IL- $1 \beta$ in macrophages [51] open the possibility for the involvement of this enzyme as a mediator of glucose actions towards the NLRP3 inflammasome. Indeed, high glucose levels may inhibit hexokinase by inducing cell accumulation of its allosteric inhibitor glucose 6-phosphate and/or the Krebs cycle intermediate citrate, both of which have been shown to promote inflammasome activation in macrophages [51].

In addition to pancreatic $\beta$-cells, in vitro exposure of endothelial cells, monocytes, macrophages, hepatocytes, adipocyte progenitor cells, or mature adipocytes to high glucose levels is associated with a proinflammatory response characterized by activation of the canonical proinflammatory $\mathrm{NF} \kappa \mathrm{B}$ signaling pathway and elevated cytokine secretion [52-56]. In terms of possible molecular mechanisms, activation of the cellular inflammatory response by high glucose levels has been attributed to the following processes: (1) enhanced production of reactive oxygen species (ROS) and oxidative stress [55], (2) activation of the MAPK pathway [54]. (3) nonenzymatic glycation and formation of advanced glycation end products (AGE) [49], (4) activation of protein kinase C (PKC) isoforms [57], (5) epigenetic and chromatin modifications [52], (6) activation of transforming growth factor- (TGF-) $\beta$-activated kinase 1 signaling [53], (7) activation of the hexosamine pathway and modification of proteins by $\mathrm{N}$-acetylglucosamine (O-GlcNAc modification) [58], and (8) inhibition of AMP-activated protein kinase (AMPK) [59]. Among those processes, which have been covered before in an excellent review article [60], we will further discuss herein the mechanisms by which exposure to high glucose levels promotes inflammation by inducing oxidative stress and spontaneous glycation and by inhibiting the energy sensor AMPK (Figure 1).

Chronic cell exposure to high glucose levels is associated with an imbalance between ROS production and antioxidant buffering resulting in cellular oxidative stress. Mechanistically, high glucose levels increase ROS production and oxidative stress by enhancing glucose oxidation through the Krebs cycle, NADH/NAD and $\mathrm{FADH}_{2} / \mathrm{FAD}$ ratios and electron flux in a stepwise manner through complexes I and III redox 
centres, which then catalyzes the transference of some of these electrons to $\mathrm{O}_{2}$ [49]. Oxygen radical species are highly reactive substances that when in excess promote organelle dysfunction and cellular damage by reacting with protein, lipids, carbohydrates, and DNA [49]. In oxidative stress, cells trigger an inflammatory response as a protective mechanism to repair cell damage and avoid death that includes activation of intracellular signaling through the $\mathrm{NF} \kappa \mathrm{B}$ pathway [61], as well as NLRP3 inflammasome-mediated IL-1 $\beta$ cleavage and secretion $[62,63]$.

In addition to oxidative stress, high glucose levels also promote inflammation by enhancing the spontaneous glycation of free amino groups of proteins, DNA, and other molecules, generating, through a series of reactions, AGE [49]. Importantly, glycation is concentration-dependent, does not require enzymatic activity, and, similarly to ROS, impairs the biological function of molecules, inducing organelle dysfunction, stress, and inflammation. In addition to glucose, other simple sugars such as fructose, galactose, and ribose, as well as phosphorylated intermediates of metabolism (glucose 6-phosphate, fructose 6-phosphate, ribose 5-phosphate, etc.), are also precursors for AGE formation [49]. Several circulating proteins such as albumin, insulin, hemoglobin, and the lipoproteins LDL, VLDL, and HDL have also been shown to undergo glycation in conditions of glucose excess, forming precursors of AGE denominated as Amadori products [49]. Among these, glycated albumin and LDL, for example, were shown to induce proinflammatory $\mathrm{NF} \kappa \mathrm{B}$ signaling, cytokine secretion, and inflammation through the activation of Amadori receptors in the target cells [64,65]. Similarly to its precursors, AGE exert part of their actions through the activation of a class of ubiquitously expressed membrane receptors of AGE (RAGE). Binding and activation of RAGE by AGE promotes an oxidative stress-dependent proinflammatory cell response characterized by $\mathrm{NF} \kappa \mathrm{B}$ activation, increased cytokine secretion, activation of cyclooxygenase and prostaglandin synthesis, and enhanced recruitment and activation of both innate and adaptive immune system [49, 66-68]. Supporting this notion, RAGE activation promotes $\mathrm{NF} \kappa \mathrm{B}$ activation, IL- 6 and TNF- $\alpha$ secretion, and polarization of bone marrow-derived macrophages to a proinflammatory M1 profile [69]. In contrast, RAGE deletion is associated with reduced leukocyte recruitment and inflammation of the peritoneal cavity in a model of thioglycollate-induced acute peritonitis [70]. Altogether, these findings indicate that modification of cellular constituents by ROS and/or glycation may be responsible, at least in part for the inflammatory response induced by hyperglycemia.

One important nutrient and energy sensor that detects variations in cell glucose availability is the heterotrimeric protein AMP-activated protein kinase (AMPK), a well-conserved, ubiquitously expressed, serine/threonine kinase whose activity is modulated by changes in ADP/ATP ratio and cell energy status. In situations of energy scarcity, AMPK is activated by an elevation in the ADP/ATP ratio, whereas the opposite, that is, a reduction in AMPK activity, occurs in situations of energy surplus and reduced ADP/ATP ratio [71]. Mechanistically, AMPK is activated by ADP and more potently by AMP through a process that involves the binding of adenine nucleotides to the AMPK $\gamma$ subunit. This changes its conformation and leaves it not only prone to the phosphorylation at the $\alpha$ subunit Thr172 residue by liver kinase B-1 (LKB-1) but also resistant to the dephosphorylation by protein phosphatase 2A [71]. When active, AMPK promotes glucose uptake, fatty acid oxidation, mitochondrial biogenesis, and other energy-generating catabolic processes and inhibits synthetic pathways, such as fatty acid and protein syntheses [71]. In addition to its role in the regulation of metabolism, several pieces of evidence support a likely involvement of AMPK as an important modulator of obesityand hyperglycemia-induced inflammation. Under these conditions characterized by energy surplus, AMPK Thr172 phosphorylation and activity are broadly and markedly reduced. Such a phenotype is also seen upon treatment of bone marrow-derived macrophages and dendritic cells with LPS and other proinflammatory molecules [72-75]. Indeed, in vitro macrophage AMPK inhibition by either RNAi or expression of AMPK dominant negative or deletion of the AMPK $\beta 1$ subunit is associated with enhanced LPS-induced TNF- $\alpha$, IL-6, and cyclooxygenase-2 levels, diacylglycerol accumulation and PKC activation [72, 74]. In vivo, genetic AMPK inhibition in macrophages exacerbates obesity-associated liver and adipose tissue inflammation by increasing macrophage recruitment and polarization to a proinflammatory M1 profile [72]. In accordance with the notion emerged from the above-mentioned loss-of-function studies suggesting that AMPK activity is anti-inflammatory in nature, both in vitro and in vivo pharmacological activation of this kinase with either AICAR (5-aminoimidazole4-carboxamide ribonucleotide) or the antidiabetic drugs metformin and troglitazone or the glycolysis inhibitor 2deoxyglucose is associated with marked attenuation of LPS-induced $\mathrm{NF} \kappa \mathrm{B}$ activation, as well as iNOS and TNF- $\alpha$ expression in myocytes, adipocytes, macrophages, neutrophils, and dendritic cells [75-77]. Furthermore, recent studies have found not only that AMPK activity is increased by the anti-inflammatory molecules IL-10, TGF- $\beta$, salicylate $[74,78]$, and adiponectin [79] but also that its constitutive genetic activation in macrophages resulted in impaired production of proinflammatory cytokines and enhanced cell polarization to a M2 anti-inflammatory profile [74]. Mechanistically, AMPK seems to exert its anti-inflammatory actions by impairing intracellular proinflammatory signaling through $\mathrm{NF} \kappa \mathrm{B}$, as well as by inducing in macrophages a metabolic shift from aerobic glycolysis to oxidative pathways [74]. Altogether, these findings establish AMPK as an important pharmacological target to counteract obesity and hyperglycemia-associated inflammation.

\subsection{Amino Acid Excess and Inflammation. Metabolomic} characterization of the serum of fasting obese insulinresistant patients indicates that elevated circulating levels of branched-chain (leucine, isoleucine, and valine) and aromatic (phenylalanine, tyrosine, and tryptophan) amino acids (BCAA and AA, resp.) are not only important metabolic signatures that distinguish obese patients from lean, healthy individuals $[12,80,81]$ but also risk factors for the development of insulin resistance and T2D $[82,83]$. Despite those 
findings, it is still unknown whether BCAA have a causal role in the development of obesity-associated insulin resistance or whether elevated circulating levels of BCAA are just a metabolic consequence of this disease. In line with a possible causal contribution, supplementation of a high-fat diet with all three BCAA has deleterious effects on insulin sensitivity in rats $[81,84]$ and BCAA infusion to healthy man impaired insulin-stimulated glucose disposal in skeletal muscle [85]. Furthermore, treatment of myocytes and murine and human adipocytes with amino acids in vitro also induces insulin resistance [85, 86]. Mechanistically, this deleterious effect of BCAA on insulin sensitivity involves the activation of the nutrient and amino acid sensor mTORC1 that promotes insulin resistance by activating S6K1 and therefore the inhibitory phosphorylation of IRS-1 at serine residues. Importantly, mTORC1 is overactivated in adipose tissue, liver, and skeletal muscle of diet- and geneticinduced obese, insulin-resistant rodents [87, 88]. Another mechanism by which mTORC1 overactivation may impair IRS-1 function and induce insulin resistance is through the activation of c-JUN-N terminal kinase (JNK) as the result of exacerbated protein synthesis, endoplasmic reticulum (ER) stress, and unfolded protein response (UPR) $[89,90]$. Despite this, it is still unclear whether BCAA are implicated in obesity-associated mTORC1 overactivation and whether this complex is involved in the development of obesitylinked insulin resistance.

In favor of the notion, however, that elevated serum BCAA levels are rather a consequence of obesity and insulin resistance, both inflammation and endoplasmic reticulum stress [91], major hallmarks of these diseases, were shown to increase circulating BCAA levels by reducing rates of BCAA oxidation in adipose tissue and by enhancing skeletal muscle protein degradation [83]. Furthermore, elevated intake of BCAA was associated, independently of genetics, with lower insulin resistance, inflammation, blood pressure, and adiposity-related metabolites in female twins [92]. Such beneficial BCAA actions to metabolic health were also seen in several studies in rodents, where high BCAA intake was associated with reductions in body weight, adiposity, and glucose intolerance in diet-induced obese mice [93, 94]. Along with its beneficial effects on glucose homeostasis, BCAA were shown to exert anti-inflammatory actions. Indeed, elevated intake of BCAA was associated with reductions in muscle damage and inflammation during intensive exercise training [94], in hepatic steatosis and inflammation induced by diet-induced obesity $[95,96]$, and in chronic white adipose tissue and liver inflammation and early-phase hepatic tumorigenesis associated with obesity [97]. Extending those findings, elevating blood BCAA levels through the deletion of the mitochondrial branched-chain aminotransferase (BCATm) in mice was shown to attenuate the catabolic and proinflammatory effects of LPS and improve survival in response to bacterial infection [98].

Although the mechanisms by which BCAA modulate inflammation are not completely defined, it may involve the activation of the amino acid sensor mTORC1, a multiprotein complex composed by the highly conserved serine-threonine kinase mTOR as its catalytic core, along with the accessory proteins regulatory-associated protein of mTOR (Raptor), mammalian lethal with Sec13 protein 8 (mLST8), DEP domain-containing mTOR-interacting protein (DEPTOR), proline-rich Akt substrate 40 (PRAS40), and Tti1/Tel2 complex proteins [18]. The BCAA leucine activates mTORC1 by inducing its translocation to the lysosomes and interaction with the GTP-bound protein Ras homolog enriched in the brain (Rheb). This requires leucine binding to sestrin 2 and activation of small GTPases denominated as Ras-related GTP-binding protein (Rags), through a process that involves the protein complexes GAP activity towards Rags (GATOR) 1 and 2 and the Ragulator $[18,99]$. Importantly, mTORC1's major cellular function is to coordinate processes such as cell growth, proliferation, metabolism, autophagy, and survival according to nutrient and growth factor availability [18].

In addition to amino acids and growth factors, mTORC1 activity is also upregulated by proinflammatory mediators such as LPS via TLR-4-mediated activation of either IKK $\beta[100,101]$ or PI3K-Akt $[102,103]$ and by the anti-inflammatory cytokines IL-4 and IL-13 [104], indicating that this complex may have a role in the regulation of inflammation and immune function. Indeed, pharmacological mTORC1 inhibition with the macrolide rapamycin is associated with an exacerbation of obesity-associated adipose tissue inflammation, as evidenced by the enhanced tissue recruitment and polarization of macrophages to a proinflammatory phenotype and expression of proinflammatory cytokines IL- $1 \beta$ and TNF- $\alpha[104,105]$. In accordance to these findings, mTORC1 inhibition with rapamycin was shown to enhance the spontaneous polarization of human monocytes in vitro and peripheral blood mononuclear cells in vivo to a proinflammatory profile [106, 107]; such a response is also seen in murine bone marrow-derived macrophages in vitro [104]. Importantly, Raptor deletion and therefore mTORC1 deficiency in adipocytes, but not myeloid cells [108], promoted adipose tissue inflammation, NLRP3inflammasome activation, leukocyte recruitment, and local cytokine production [109]. Interestingly, this inflammatory response, which occurred despite of a drastic reduction in adipose tissue mass, was mediated by an increase in the local production of ceramides [109] (Figure 2).

The effects of mTORC1 constitutive activation in embryonic fibroblasts and macrophages have also been investigated reporting contrasting results. Constitutive mTORC1 activation through the inactivation of either TSC1 or TSC2 in human monocytes, murine myeloid cells, and embryonic fibroblasts was shown to (1) limit the inflammatory response by blocking LPS-induced NF $\kappa$ B activation and increasing IL-10 production [107], (2) induce in a cell autonomous manner granuloma formation and lung and liver infiltration of alternatively activated M2 macrophages and reduce lung iNOS [110], (3) increase the activity of the energy sensor AMPK that exerts anti-inflammatory actions [111], and (4) protect from diet-induced obesity and adipose tissue inflammation by promoting the polarization of adipose tissueresident macrophages to a M2 phenotype (Paschoal et al., unpublished observations). Noteworthily, a recent study found that the Akt-mTORC1 pathway is an important mediator of macrophage polarization to a M2 phenotype induced 


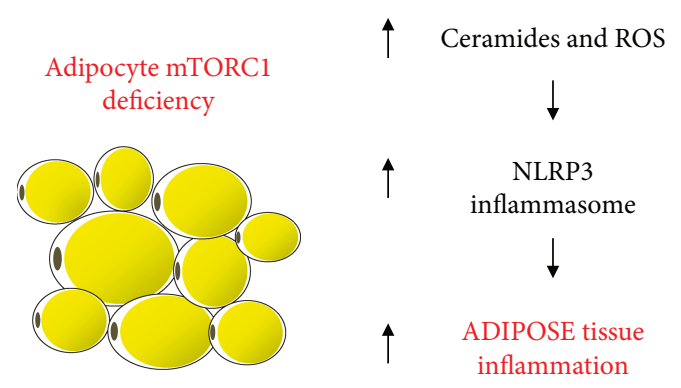

Figure 2: Mechanisms underlying adipose tissue chronic inflammation induced by mTORC1 deficiency in adipocytes. ROS: reactive oxygen species.

by IL-4, through a mechanism that involves activation of ATP-citrate lyase, histone acetylation, and transcriptional induction of a subset of M2 genes [112]. In contrast to those findings, however, Tsc1-deficient bone marrow-derived macrophages (BMDM) were refractory to $\mathrm{M} 2$ polarization induced by IL- 4 and displayed enhanced M1 polarization, nitric oxide (NO) production, and cytokine secretion induced by toll-like receptor ligands [113, 114]. Surprisingly, another study found that Tsc1-deficient macrophages exhibited enhanced polarization to both M1 and M2 phenotypes both at steady-state condition and induced by either LPS or IL-4 [115].

In spite of the apparent contradictory findings, the scenario emerging from the aforementioned studies is that mTORC1 is an important mediator of both proinflammatory $\mathrm{M} 1$ and anti-inflammatory M2 macrophage responses (Figure 3). Indeed, this is in accordance with mTORC1's role in the regulation of processes such as protein, lipid and nucleotide syntheses, autophagy, and lysosome formation that are vital to macrophages independently of their phenotype. Accordingly with this notion, mTORC1 activity is increased by proinflammatory molecules (LPS, TNF- $\alpha$, and IFN- $\gamma$ ) in M1 macrophage polarization [100, 102, 104], as well as by the M2 macrophage-promoting cytokines (IL4 and IL-13) [104, 112]. Furthermore, mTORC1 induces metabolic processes that are important for $\mathrm{M} 1$ and $\mathrm{M} 2$ macrophage functions, namely, aerobic glycolysis and oxidative metabolism, respectively, through mechanisms that involve activation of hypoxic-inducible factor $1 \alpha$ (HIF-1 $\alpha)$ in the former (M1 aerobic glycolysis) and the peroxisome proliferator-activated receptor $\gamma(\operatorname{PPAR} \gamma)$, PPAR coativactor $1 \alpha(\mathrm{PGC} 1 \alpha)$, and mitochondrial biogenesis in the latter (M2 oxidative metabolism) [116]. Altogether, these findings suggest that mTORC1 is an important mediator of both classic M1 and alternative M2 macrophage polarizations, exerting its functions according to the underlying stimuli context (Figure 3). In addition to macrophages, mTORC1 seems to play an important role regulating T lymphocyte proliferation, migration, differentiation, metabolism, and activation as elegantly reviewed before [117].

Similarly to complex 1, mTORC2 is also activated by both M1 (LPS and IFN- $\gamma$ ) and M2 (IL-4 and IL-13) inducers playing an important role in regulation of macrophage polarization and function (Figure 4). More specifically, deletion of rapamycin-insensitive companion of MTOR (RICTOR) and therefore mTORC2 deficiency in myeloid cells was shown to enhance both polarization of bone marrow-derived macrophages to the M1 profile and the proinflammatory cytokine secretion induced by LPS and other TLR ligands and to reduce the expression of M2-related genes [103]. Furthermore, mice with mTORC2 disruption in myeloid cells had higher circulating TNF- $\alpha$ levels and mortality in a model of acute septic shock induced by high dose of LPS [103]. Mechanistically, this enhanced M1 polarization induced by mTORC2 deficiency was attributed to FOXO1 activation due to reduced Akt activity and therefore enhanced transcription of proinflammatory genes [118]. Subsequent studies have also shown that mTORC2 is essential for proper bone marrow-derived macrophage polarization to a M2 profile. Indeed, mTORC2-deficient M2 macrophages were shown to display impaired glucose metabolism and reduced PPAR $\gamma$ content, mitochondrial biogenesis, and fatty acid oxidation, effects that are mediated by Akt and, at least in part, by the transcriptional factor interferon regulatory factor 4 (IRF4) [119].

\subsection{Fatty Acid Excess and Inflammation. Evidence suggests} that lipids, especially fatty acids, play an important role not only in obesity development but also as a linking factor between the excessive adiposity and development of associated diseases [120]. Indeed, elevated intake of diets containing high amounts of saturated fatty acids induces obesity and its major complications including inflammation, insulin resistance, and ectopic lipid deposition, among others. Recent studies, however, have indicated that more important than quantity, diet fatty acid composition has major implications in the development of "metainflammation." High intake of diets rich in saturated fatty acids, for instance, activates the innate immune toll-like receptor 4 (TLR4) promoting chronic low-grade inflammation, insulin resistance, and cardiovascular disease [121]. In the same line, $\omega-6$ polyunsaturated fatty acid-enriched diets were shown to be proinflammatory and deleterious to the cardiovascular function $[121,122]$. In spite of the deleterious effects of saturated and $\omega-6$ polyunsaturated fatty acids to metabolic health, other types of lipids have preventive and/or therapeutic properties that could be explored to counteract metabolic diseases. Among beneficial lipids, $\omega-3$ polyunsaturated and short-chain fatty acids were demonstrated to have antiinflammatory, anti-carcinogenic, hypolipidemic, and weight loss-inducing properties $[123,124]$. Below, we discuss the modulation of "metainflammation" by specific types of fatty acids (Figure 5).

1.6. Saturated Fatty Acids (SFAs). Saturated fatty acids such as lauric (C12:0), miristic (C14:0), palmitic (C16:0), and stearic (C18:0) are commonly found in foods of animal source such as dairy products and meat, and some vegetables as coconut and palm oil, being therefore the most prevalent saturated fatty acids found in human diet. Many studies have associated an elevated intake of saturated fatty acids with a higher prevalence of obesity, cardiovascular disease, diabetes, and insulin resistance, diseases that share chronic low-intensity inflammation as a common feature [125]. 


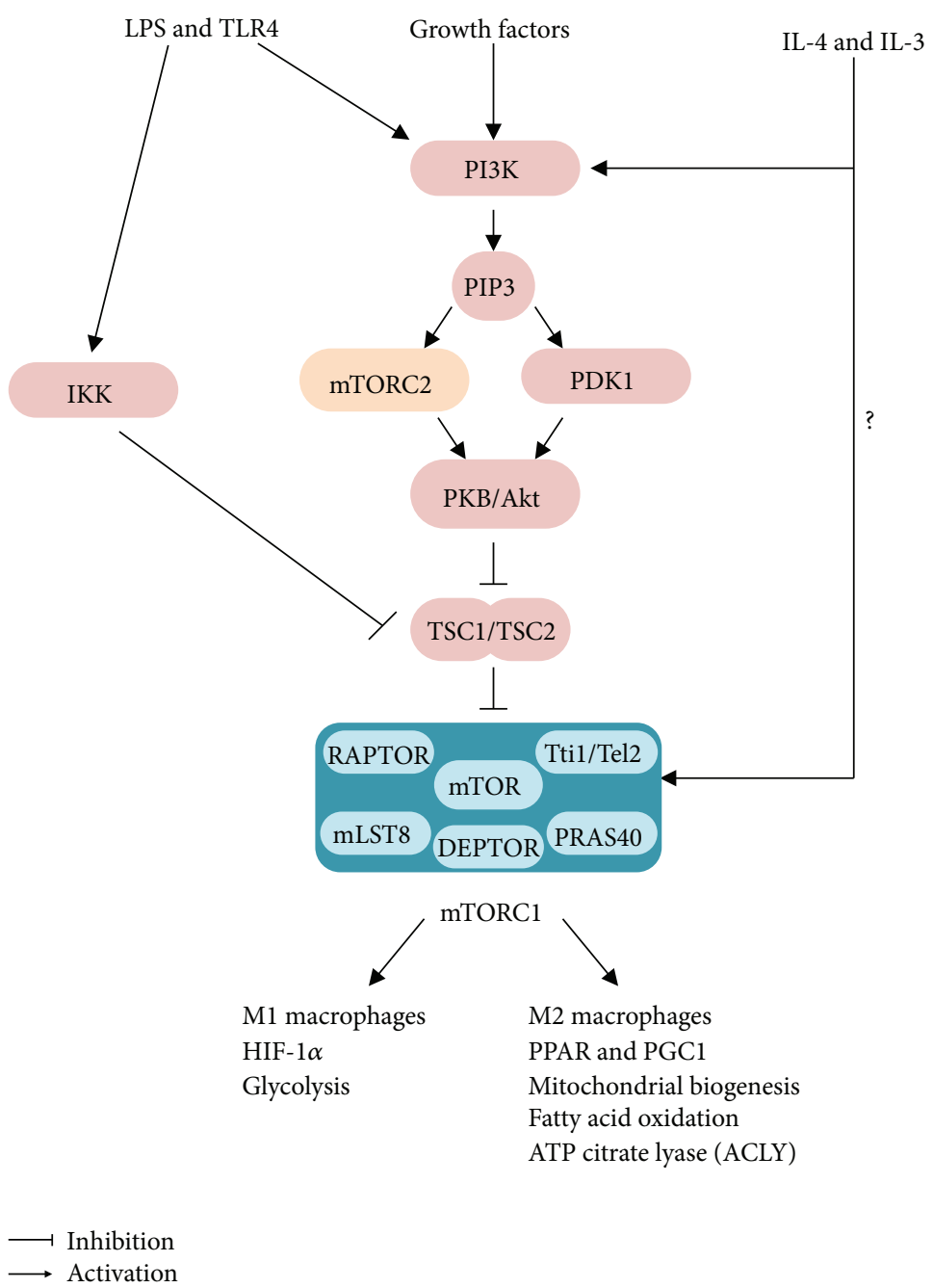

FIGURE 3: $\mathrm{mTORC1}$ is activated in both M1 and M2 polarization and regulates important metabolic processes at both conditions. AA: amino acids; ACLY: ATP citrate lyase; HIF- $1 \alpha$ : hypoxic inducible factor $1 \alpha$; IL-4: interleukin 4 ; IL-13: interleukin 13 ; PGC1 $\alpha$ : PPAR $\gamma$ coactivator $1 \alpha$; $\operatorname{PPAR} \gamma$ : peroxisome proliferator-activated receptor $\gamma$; TLR4: toll like receptor 4 .

Therefore, since 1961, the American Heart Association recommends a reduction in the intake of foods rich in saturated fatty acids aiming to reduce the prevalence of those chronic metabolic diseases [126].

At the molecular level, saturated fatty acids promote inflammation through several mechanisms that include activation of the TLR4-IKK-NFKB signaling pathway and NLRP3 inflammasome, enhanced ROS production and oxidative stress, mitochondrial dysfunction, ER stress, accumulation of diacylglycerol and ceramides, and PKC activation, among others [63, 127-132]. Saturated fatty acids are potent activators of the pattern recognition receptor TLR4, which is also activated by LPS and others PAMPs and DAMPs and has a major role in the regulation of innate immune response $[128,133,134]$. Activation of TLR4 by saturated fatty acids elicits, through the activation of $\mathrm{NF} \kappa \mathrm{B}$, the secretion of several proinflammatory cytokines such as TNF- $\alpha$, IL-6, and MCP-1, which are involved in the development of obesityassociated inflammation and insulin resistance $[128,133$, 134]. In addition, saturated fatty acids were shown to activate
NLRP3 inflammasome-mediated IL- $1 \beta$ production in macrophages, such an effect that seems to involve AMPK inactivation, autophagy inhibition, and enhanced mitochondrial ROS production [129].

In addition to inflammatory signaling, chronic tissue exposure to high levels of saturated fatty acids may promote insulin resistance by increasing tissue content of the lipids diacylglycerol and ceramides. Diacylglycerol accumulation promotes insulin resistance by activating the PKC $\Theta$ and $\varepsilon$ impairing IRS tyrosine phosphorylation and therefore downstream insulin signaling [135]. Ceramides, on the other hand, consist of a family of lipids structurally formed by a sphingosine base bound to a fatty acid that promote insulin resistance by two nonmutually exclusive mechanisms, involving either the allosteric activation of protein phosphatase 2A (PP2A), which dephosphorylates and inhibits Akt [136], or the activation of atypical PKC $\lambda / \zeta$, which phosphorylates Akt pleckstrin domain at residue 34 impairing its translocation to the membrane and subsequent activation $[137,138]$. Ceramides have been also shown to modulate inflammatory processes 

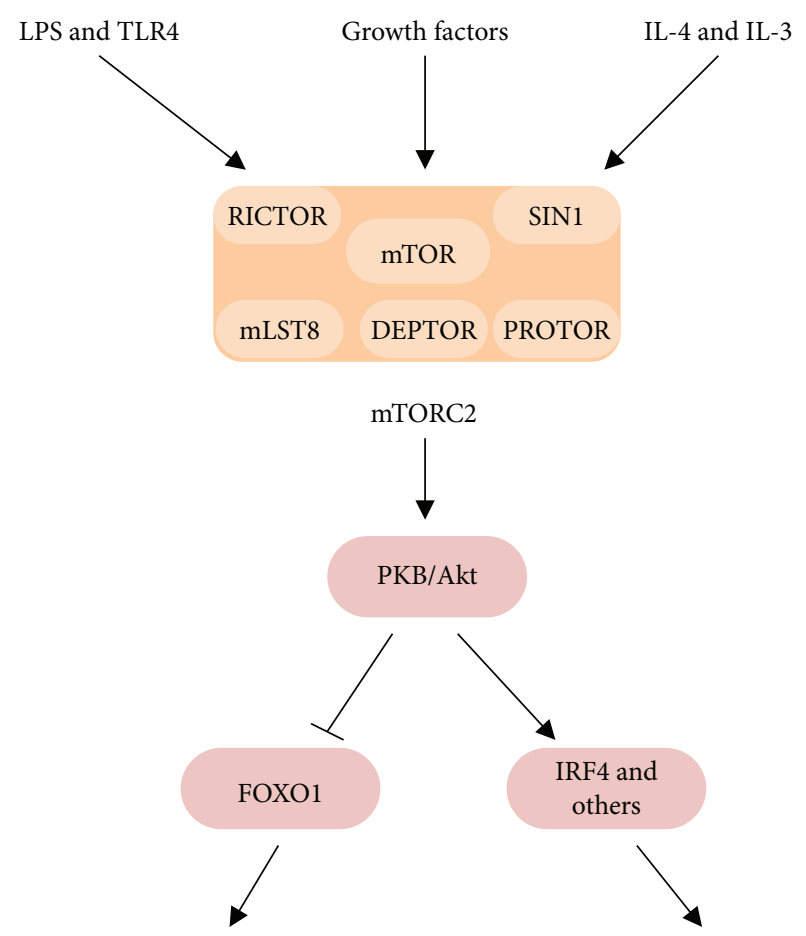

M1 macrophages TNF- $\alpha$

IL- $1 \beta$
M2 macrophages PPAR $\alpha$

Oxidative metabolism Mitochondrial biogenesis Fatty acid oxidation

\section{$\longrightarrow$ Inhibition \\ $\longrightarrow$ Activation}

Figure 4: mTORC2 is activated in both M1 and M2 polarization and regulates important metabolic processes at both conditions. IL$1 \beta$ : interleukin $1 \beta$; IL-4: interleukin 4; IL-13: interleukin 13; IRF4: interferon regulatory factor 4; LPS: lipopolysaccharide; PKB: protein kinase B; PPAR $\gamma$ : peroxisome proliferator-activated receptor $\gamma$; TLR4: toll-like receptor 4 ; TNF- $\alpha$ : tumor necrosis factor- $\alpha$.

displaying either pro- or anti-inflammatory responses, as elegantly reviewed before [139]. Briefly, proinflammatory actions of ceramides involve activation of TLR4 signaling as a result of ceramide interaction with this receptor, formation of TLR4-lipid raft complex, and activation of NLRP3 inflammasome-mediated IL- $\beta$ and IL-18 production [139].

1.7. Monounsaturated Fatty Acids (MUFAs). In contrast to their saturated counterparts, elevated intake of monounsaturated fatty acids is associated with reduced adipocyte hypertrophy, adipose tissue infiltration of proinflammatory macrophages, and inflammation and improved insulin sensitivity [140-142]. In line with these findings, oleic acid (C18:1), the most abundant monounsaturated fatty acid found in human diet, promotes the secretion of the anti-inflammatory adipokine adiponectin and impairs the proinflammatory resistin in 3T3-L1 adipocytes [143]. Furthermore, diet supplementation with macadamia oil, a rich source of oleic acid, improves lipid metabolism and glucose homeostasis in diet-induced obese mice [144, 145].
Although oleic acid is the major fatty acid found in macadamia oil, this nut is also an important natural source of the monounsaturated fatty acid palmitoleic acid (C16:1). This fatty acid, which can be obtained either from diet or from endogenous synthesis by stearoyl-CoA desaturase- (SCD-) 1 mainly in adipose tissue and liver, was shown to enhance whole-body glucose disposal and attenuate hepatic steatosis in diet-induced obese mice $[146,147]$ and protect $\beta$-cell from death induced by palmitic acid [148, 149]. In line with those findings, a two-week supplementation with palmitoleic acid improved glucose homeostasis and insulin sensitivity, reduced hepatic steatosis, and increased skeletal muscle fatty acid oxidation in diet-induced obese mice [150]. In addition, palmitoleic acid also increased hepatic oxidative metabolism by activating the AMPK-fibroblast growth factor- (FGF-) 21-peroxisome proliferator-activated receptor (PPAR) $\alpha$ axis [151]. In addition to these beneficial metabolic actions, palmitoleic acid was recently shown to have antiinflammatory properties. Indeed, macrophages pretreated with palmitoleic acid secrete less proinflammatory cytokines after either LPS or palmitic acid treatment $[152,153]$ and displayed reduced macrophage polarization to a $\mathrm{M} 1$ phenotype in part due to AMPK activation [154]. Altogether, these findings support a possible utilization of palmitoleic acid supplementation as a nonpharmacological strategy to reduce obesity-associated chronic low-grade inflammation [155]. Interestingly, palmitoleic acid was also shown to enhance lipolysis, glucose uptake, and GLUT-4 content in adipocytes, such effects that are mechanistically induced by PPAR $\alpha$ and AMPK activation, respectively $[156,157]$. Whether palmitoleic acid also has anti-inflammatory actions in white adipose tissue needs to be investigated.

1.8. $\omega-6$ Polyunsaturated Fatty Acids. In addition to the high content of saturated fatty acids, another main feature defining the Western diet is the elevated $\omega-6$ and low $\omega-3$ polyunsaturated fatty acid contents [158]. Evidence indicates that this high $\omega-6 / \omega-3$ ratio dietary pattern is one of the main causes of the rise in obesity and associated metabolic diseases seen in the last decades [159]. Linoleic acid, the most abundant $\omega-6$ fatty acid in the Western diet, has important actions on cholesterol metabolism, as well as on inflammation. More specifically, linoleic acid was shown to lower blood cholesterol levels by increasing both hepatic clearance of lowdensity lipoprotein (LDL) [160] and production of bile acids and to be proinflammatory by activating $\mathrm{NF} \kappa \mathrm{B}$ in endothelial cells [161], although this does not seem to be reflected by systemic markers of inflammation [162]. Linoleic acid can be enzymatically converted to arachidonic acid, a $\omega-6$ fatty acid that acts as the precursor for the synthesis of two classes of lipid mediators known as eicosanoids (prostaglandins, prostacyclins, thromboxane, and leukotrienes) and endocannabinoids (anandamide and 2-arachidonoylglycerol, among others). Eicosanoids are potent regulators of inflammation and immune function, being therefore implicated in the development of chronic metabolic diseases such as obesity, insulin resistance, and cancer [159]. Indeed, recent studies have shown that the eicosanoid leukotriene $\mathrm{B} 4$ promotes adipose tissue inflammation by inducing tissue macrophage 


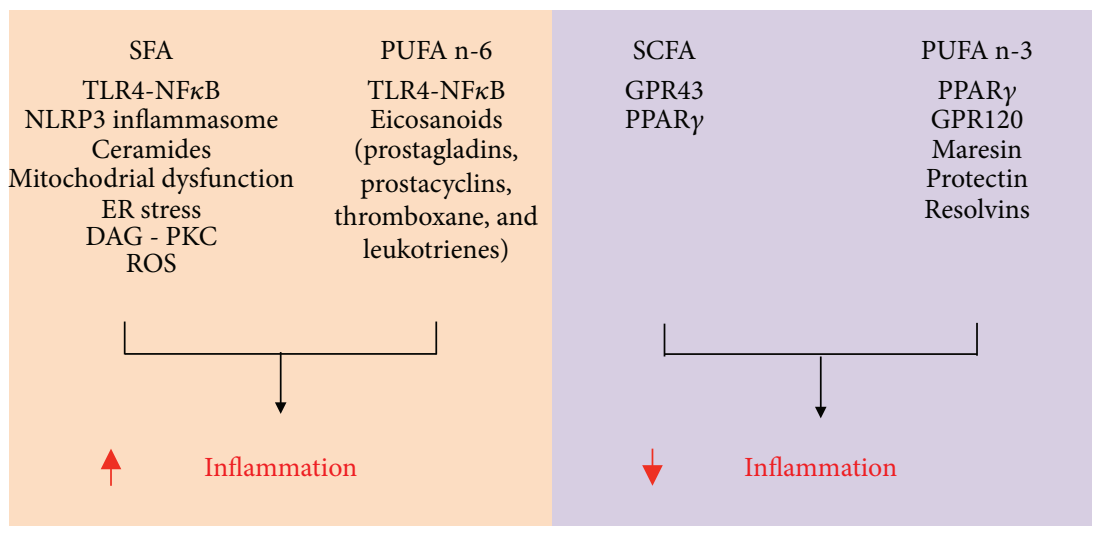

FIGURE 5: General overview of the mechanisms by which different fatty acids modulate inflammation. AMPK: AMP-activated protein kinase; DAG: diacylglycerol; ER: endoplasmic reticulum; GPR: G protein-coupled receptor; PKC: protein kinase C; PPAR: peroxisome proliferatoractivated receptor; PUFA n-6: polyunsaturated n-6 fatty acids; PUFA n-3: polyunsaturated n-3 fatty acids; ROS: reactive oxygen species; SCFA: short-chain fatty acids; SFA: saturated fatty acids; TLR: toll-like receptor.

chemotaxis and polarization to the proinflammatory M1 profile, as well as insulin resistance in the liver and skeletal muscle [163]. Interestingly, opposite effects were seen upon treatment with the eicosanoid lipoxin A4, which reduced adipose tissue inflammation as evidenced by diminished tissue expression of proinflammatory cytokines and higher macrophage polarization to the anti-inflammatory M2 profile [164]. These findings indicate that different eicosanoids have distinct roles in the regulation of adipose tissue inflammation and therefore in the development of obesityassociated insulin resistance.

1.9. $\omega$-3 Polyunsaturated Fatty Acids. It has been known since the 1980s that fish oil, which is rich in the $\omega$-3 polyunsaturated fatty acids eicosapentaenoic acid (EPA) (C20:5, $\omega-3)$ and docosahexaenoic acid (DHA) (C22:6, $\omega-3)$, has many beneficial health effects. Indeed, increased whole-body $\omega$-3 polyunsaturated fatty acid availability either genetically or through dietary supplementation is associated with hypotriglyceridemia [165], improvement in cardiovascular health by diminishing platelet aggregation and thromboxane levels $[166,167]$, and attenuation of systemic inflammation [168, 169]. More recently, $\omega-3$ polyunsaturated fatty acids were also shown to protect mice from diet-induced obesity, insulin resistance, hepatic steatosis, and tumorigenesis; such effects were attributed at least in part to the anti-inflammatory properties of these fatty acids $[123,170]$. Several mechanisms have been proposed to account for the anti-inflammatory actions of $\omega-3$ polyunsaturated fatty acids including the activation of the plasma membrane $G$ protein-coupled receptor 120 (GPR120) [171], activation of the nuclear receptor PPAR $\gamma$ [172], inhibition of the conversion of $\omega-6$ fatty acids into eicosanoids [159], alterations in plasma membrane composition, fluidity and signaling [173], and induction of the synthesis of proresolution lipid mediators such as resolvins, protectins, and maresins [174]. Among these, recent studies have shown that activation of GPR120, a receptor mainly expressed in adipocytes and macrophages, may be essential to the anti-inflammatory actions of $\omega-3$ polyunsaturated fatty acids. Indeed, both EPA and DHA were shown to impair
LPS-induced JNK activation and TNF- $\alpha$ and IL- 6 secretion by RAW 264.7 cells and 3T3-L1 adipocytes in vitro through the activation of GPR120 [171]. In line with those findings, mice deficient in GPR120 were resistant to the antiinflammatory actions and the improvement in whole-body glucose homeostasis induced by the intake of diet rich in $\omega$ 3 polyunsaturated fatty acids [171]. Two recent studies, however, have challenged the notion that GPR120 activation is mandatory for those $\omega-3$ polyunsaturated fatty acid actions. These studies have shown that intake of diet rich in $\omega$-3 polyunsaturated fatty acids was equally effective in reducing body weight gain, improving glucose homeostasis and attenuating inflammation in a new generated mice deficient in GPR120 and wild-type controls $[175,176]$.

Another mechanism by which $\omega-3$ polyunsaturated fatty acids may reduce inflammation is by enhancing the synthesis of proresolution lipid mediators, namely, protectins, resolvins, and maresins. Both EPA (e-series) and DHA (d-series) are precursors for the synthesis of these mediators [177], which have been shown to control the magnitude and duration of inflammatory processes in several rodent models of chronic diseases [174]. In line with this notion, the resolvin $\mathrm{E} 1$ and protectin D1 were shown to improve insulin sensitivity and reduce hepatic steatosis and adipose tissue inflammation in diet-induced obese mice [178], whereas resolvin D1 improved glucose tolerance, increased adiponectin secretion, and reduced adipose tissue macrophage recruitment and formation of crown-like structures in genetically obese $d b / d b$ mice [179]. Furthermore, protectin DX improved glucose homeostasis in $\mathrm{db} / \mathrm{db}$ mice by promoting IL-6 secretion from skeletal muscle without affecting white adipose tissue inflammation [180]. Further studies characterizing the biological function of already described and new metabolites from EPA and DHA are required to explore the promising usage of these lipids in the prevention and/or treatment of chronic inflammatory diseases.

1.10. Short-Chain Fatty Acids (SCFA). The short-chain fatty acids acetate $\left(\mathrm{C}_{2}\right)$, propionate $\left(\mathrm{C}_{3}\right)$, and butyrate $\left(\mathrm{C}_{4}\right)$ are produced at the intestine by anaerobic fermentation of 
nondigestible dietary fibers, being readily absorbed and used as energy source by colonocytes and by other body tissues including liver and muscle [181]. In addition to their role as metabolic substrates, short-chain fatty acids regulate several aspects of inflammatory processes such as the recruitment of circulating leukocytes in the inflammatory site, production of chemokines and cytokines, expression of adhesion molecules, production of eicosanoids and reactive oxygen species, and lymphocyte proliferation and differentiation [124]. Studies evaluating the effects of short-chain fatty acids in animal models of inflammatory diseases including acute kidney injury, obesity, and T2D indicate that these molecules are potent anti-inflammatory agents [182, 183]. Indeed, sodium butyrate administration to obese and diabetic $d b / d b$ mice markedly attenuated adipose tissue inflammation as evidenced by reduced tissue lymphocyte infiltration, cytokine expression and NLRP3 inflammasome activity, and improved glucose homeostasis [184]. Furthermore, propionate reduced the proinflammatory response and cytokine secretion induced by LPS in human adipose tissue explants and macrophages [185], whereas butyrate activates the anti-inflammatory Treg cells suppressing the secretion of cytokines via activation of membrane $G$ protein-coupled receptors GPR43/FFAR2 [186]. These receptors, which are mainly expressed in adipose tissue (adipocytes), intestines, and immune cells and signals through $G_{\mathrm{q}}$ and $\mathrm{G}_{\mathrm{i} / \mathrm{o}}$, ERK, MAPK, and intracellular $\mathrm{Ca}^{2+}$, are important mediators of short-chain fatty acid actions [187]. Noteworthily, as recently reviewed [188], inconsistent results have been obtained in studies with GPR43 deletion in mice, which precludes a full appreciation of the role of these receptors in chronic inflammatory conditions. Finally, short-chain fatty acids were also shown to impair LPS-induced production of nitric oxide and proinflammatory cytokines in the macrophage cell line RAW264.7; such effect seems to involve inhibition of $\mathrm{NF} \kappa \mathrm{B}$ signaling [189].

In addition to inflammation, short-chain fatty acids also have important effects on energy homeostasis. Recent studies have found that diet enrichment with 5\% shortchain fatty acids reduced body weight, adiposity, and hepatic steatosis in diet-induced obese mice by downregulating the activity of the nuclear receptor PPAR $\gamma$ [182], whereas nanoparticle-delivered acetate reduced diet-induced body weight gain, hepatic steatosis, and adiposity by enhancing hepatic mitochondrial function and inducing adipose tissue browning [190].

1.11. Newly Identified Lipids and Inflammation. The development of highly-sensitive OMICS techniques (lipidomic, metabolomic, genomic, transcriptomic, epigenomic, and proteomic) in the last decades has allowed the large-scale study of different classes of molecules in distinct compartments and conditions. Among those, metabolomic profiling and lipidomic profiling have emerged as promising methodologies to uncover new metabolites/lipids that either predict or are involved in the development of insulin resistance/ T2D. Recently, a metabolomic study of the plasma of 399 nondiabetic subjects with a wide range in degree of insulin sensitivity and glucose tolerance identified a group of three metabolites ( $\alpha$-hydroxybutyrate, oleate, and L-glycerylphosphorylcholine) that together could predict the development of insulin resistance [191]. Furthermore, lipidomic characterization of obese, but insulin-sensitive mice, identified a class of endogenously synthesized lipids denominated as branched fatty acid esters of hydroxy fatty acids (FAHFAs) that improves glucose homeostasis and insulin sensitivity and reduces adipose tissue inflammation in diet-induced obese mice [192]. These are only two among many examples of OMICS application to the study of different aspects of obesity-associated inflammation and insulin resistance. These highly sensitive techniques will help us both to unveil the many molecules involved in the development of these diseases and provide major insights in the novel strategies to prevent and treat them.

\section{Conclusions}

There is an established body of literature indicating that nutrients and nutrient sensors are important players involved in the development and maintenance of obesityassociated inflammation and insulin resistance. In these studies, important advances have been made in the characterization of the mechanisms by which nutrients exert their actions, resulting in the unveiling of new therapeutic targets for the treatment of metabolic diseases. Despite this progress, we are far from having the complete understanding about the complex interaction between nutrients and obesity. Indeed, with the advances of techniques such as metabolomics and lipidomics, new nutrient-related molecules are being discovered and characterized for their potential implication in the development of obesity and insulin resistance. The characterization of nutrients and derived metabolites that present proresolution properties towards obesity-associated chronic low-grade systemic inflammation is of major importance if we are to develop novel, effective therapies to prevent metabolic and cardiovascular complications associated with this disease.

\section{Conflicts of Interest}

The authors declare no conflict of interest that would prejudice the impartiality of this scientific work.

\section{Acknowledgments}

Funding was provided by Fundação de Amparo à Pesquisa do Estado de São Paulo (FAPESP) to Alex S. Yamashita (no. 13/15825-5), Thiago Belchior (no. 15/22983-1), and William T. Festuccia (nos. 10/52191-6 and 15/19530-5). The authors thank Marina da Costa Rosa for the fruitful discussion during the development of this article.

\section{References}

[1] C. J. Nolan, P. Damm, and M. Prentki, "Type 2 diabetes across generations: from pathophysiology to prevention and management," Lancet, vol. 378, no. 9786, pp. 169-181, 2011.

[2] I. J. Neeland, P. Poirier, and J. P. Després, "Cardiovascular and metabolic heterogeneity of obesity: clinical challenges 
and implications for management," Circulation, vol. 137, no. 13, pp. 1391-1406, 2018.

[3] K. Ogurtsova, J. D. da Rocha Fernandes, Y. Huang et al., "IDF diabetes atlas: global estimates for the prevalence of diabetes for 2015 and 2040," Diabetes Research and Clinical Practice, vol. 128, pp. 40-50, 2017.

[4] A. Guilherme, J. V. Virbasius, V. Puri, and M. P. Czech, "Adipocyte dysfunctions linking obesity to insulin resistance and type 2 diabetes," Nature Reviews Molecular Cell Biology, vol. 9, no. 5, pp. 367-377, 2008.

[5] M. P. Czech, "Insulin action and resistance in obesity and type 2 diabetes," Nature Medicine, vol. 23, no. 7, pp. 804814, 2017.

[6] S. M. Reilly and A. R. Saltiel, "Adapting to obesity with adipose tissue inflammation," Nature Reviews Endocrinology, vol. 13, no. 11, pp. 633-643, 2017.

[7] J. Y. Huh, Y. J. Park, M. Ham, and J. B. Kim, "Crosstalk between adipocytes and immune cells in adipose tissue inflammation and metabolic dysregulation in obesity," Molecules and Cells, vol. 37, no. 5, pp. 365-371, 2014.

[8] S. P. Weisberg, D. McCann, M. Desai, M. Rosenbaum, R. L. Leibel, and A. W. Ferrante Jr, "Obesity is associated with macrophage accumulation in adipose tissue," The Journal of Clinical Investigation, vol. 112, no. 12, pp. 1796-1808, 2003.

[9] K. L. Hoehn, C. Hohnen-Behrens, A. Cederberg et al., "IRS1independent defects define major nodes of insulin resistance," Cell Metabolism, vol. 7, no. 5, pp. 421-433, 2008.

[10] M. F. Gregor and G. S. Hotamisligil, "Inflammatory mechanisms in obesity," Annual Review of Immunology, vol. 29, no. 1, pp. 415-445, 2011.

[11] L. Chantranupong, R. L. Wolfson, and D. M. Sabatini, "Nutrient-sensing mechanisms across evolution," Cell, vol. 161, no. 1, pp. 67-83, 2015.

[12] S. Rauschert, O. Uhl, B. Koletzko, and C. Hellmuth, "Metabolomic biomarkers for obesity in humans: a short review," Annals of Nutrition and Metabolism, vol. 64, no. 3-4, pp. 314-324, 2014.

[13] E. M. Bailyes, B. T. Navé, M. A. Soos, S. R. Orr, A. C. Hayward, and K. Siddle, "Insulin receptor/IGF-I receptor hybrids are widely distributed in mammalian tissues: quantification of individual receptor species by selective immunoprecipitation and immunoblotting," Biochemical Journal, vol. 327, no. 1, pp. 209-215, 1997.

[14] M. Federici, O. Porzio, L. Zucaro et al., "Increased abundance of insulin/IGF-I hybrid receptors in adipose tissue from NIDDM patients," Molecular and Cellular Endocrinology, vol. 135, no. 1, pp. 41-47, 1997.

[15] R. A. Haeusler, T. E. McGraw, and D. Accili, "Biochemical and cellular properties of insulin receptor signalling," Nature Reviews Molecular Cell Biology, vol. 19, no. 1, pp. 31-44, 2018.

[16] F. S. Thong, C. B. Dugani, and A. Klip, "Turning signals on and off: GLUT4 traffic in the insulin-signaling highway," Physiology, vol. 20, pp. 271-284, 2005.

[17] L. Rui, "Energy metabolism in the liver," Comprehensive Physiology, vol. 4, no. 1, pp. 177-197, 2014.

[18] R. A. Saxton and D. M. Sabatini, "mTOR signaling in growth, metabolism, and disease," Cell, vol. 169, no. 2, pp. 361-371, 2017.

[19] H. Gehart, S. Kumpf, A. Ittner, and R. Ricci, "MAPK signalling in cellular metabolism: stress or wellness?," EMBO Reports, vol. 11, no. 11, pp. 834-840, 2010.
[20] F. Tremblay, S. Brûlé, S. Hee Um et al., "Identification of IRS-1 Ser-1101 as a target of S6K1 in nutrient- and obesityinduced insulin resistance," Proceedings of the National Academy of Sciences of the United States of America, vol. 104, no. 35, pp. 14056-14061, 2007.

[21] Y. Yu, S. O. Yoon, G. Poulogiannis et al., "Phosphoproteomic analysis identifies Grb10 as an mTORC1 substrate that negatively regulates insulin signaling," Science, vol. 332, no. 6035, pp. 1322-1326, 2011.

[22] P. P. Hsu, S. A. Kang, J. Rameseder et al., "The mTORregulated phosphoproteome reveals a mechanism of mTORC1-mediated inhibition of growth factor signaling," Science, vol. 332, no. 6035, pp. 1317-1322, 2011.

[23] K. J. Warren, X. Fang, N. M. Gowda, J. J. Thompson, and N. M. Heller, "The TORC1-activated proteins, p70S6K and GRB10, regulate IL-4 signaling and M2 macrophage polarization by modulating phosphorylation of insulin receptor substrate-2," Journal of Biological Chemistry, vol. 291, no. 48, pp. 24922-24930, 2016.

[24] G. S. Hotamisligil, N. S. Shargill, and B. M. Spiegelman, "Adipose expression of tumor necrosis factor-alpha: direct role in obesity-linked insulin resistance," Science, vol. 259, no. 5091, pp. 87-91, 1993.

[25] G. S. Hotamisligil and B. M. Spiegelman, "Tumor necrosis factor $\alpha$ : a key component of the obesity-diabetes link," Diabetes, vol. 43, no. 11, pp. 1271-1278, 1994.

[26] A. Festa, R. D'Agostino Jr, R. P. Tracy, S. M. Haffner, and Insulin Resistance Atherosclerosis Study, "Elevated levels of acute-phase proteins and plasminogen activator inhibitor-1 predict the development of type 2 diabetes: the insulin resistance atherosclerosis study," Diabetes, vol. 51, no. 4, pp. 1131-1137, 2002.

[27] J. A. Alvarez, P. B. Higgins, R. A. Oster, J. R. Fernandez, B. E. Darnell, and B. A. Gower, "Fasting and postprandial markers of inflammation in lean and overweight children," The American Journal of Clinical Nutrition, vol. 89, no. 4, pp. 11381144, 2009.

[28] K. T. Uysal, S. M. Wiesbrock, M. W. Marino, and G. S. Hotamisligil, "Protection from obesity-induced insulin resistance in mice lacking TNF- $\alpha$ function," Nature, vol. 389, no. 6651, pp. 610-614, 1997.

[29] T. L. Stanley, M. V. Zanni, S. Johnsen et al., "TNF- $\alpha$ antagonism with etanercept decreases glucose and increases the proportion of high molecular weight adiponectin in obese subjects with features of the metabolic syndrome," The Journal of Clinical Endocrinology \& Metabolism, vol. 96, no. 1, pp. E146-E150, 2011.

[30] H. Dominguez, H. Storgaard, C. Rask-Madsen et al., "Metabolic and vascular effects of tumor necrosis factor- $\alpha$ blockade with etanercept in obese patients with type 2 diabetes," Journal of Vascular Research, vol. 42, no. 6, pp. 517-525, 2005.

[31] M. A. Gonzalez-Gay, J. M. De Matias, C. Gonzalez-Juanatey et al., "Anti-tumor necrosis factor- $\alpha$ blockade improves insulin resistance in patients with rheumatoid arthritis," Clinical and Experimental Rheumatology, vol. 24, no. 1, pp. 83-86, 2006.

[32] I. Ferraz-Amaro, M. Arce-Franco, J. Muñiz et al., "Systemic blockade of TNF- $\alpha$ does not improve insulin resistance in humans," Hormone and Metabolic Research, vol. 43, no. 11, pp. 801-808, 2011.

[33] T. C. Wascher, J. H. Lindeman, H. Sourij, T. Kooistra, G. Pacini, and M. Roden, "Chronic TNF- $\alpha$ neutralization 
does not improve insulin resistance or endothelial function in "healthy" men with metabolic syndrome," Molecular Medicine, vol. 17, no. 3-4, pp. 189-193, 2011.

[34] C. M. Larsen, M. Faulenbach, A. Vaag et al., "Interleukin-1receptor antagonist in type 2 diabetes mellitus," The New England Journal of Medicine, vol. 356, no. 15, pp. 15171526, 2007.

[35] P. D. Cani, J. Amar, M. A. Iglesias et al., "Metabolic endotoxemia initiates obesity and insulin resistance," Diabetes, vol. 56, no. 7, pp. 1761-1772, 2007.

[36] J. R. Ussher, T. R. Koves, V. J. J. Cadete et al., "Inhibition of de novo ceramide synthesis reverses diet-induced insulin resistance and enhances whole-body oxygen consumption," Diabetes, vol. 59, no. 10, pp. 2453-2464, 2010.

[37] P. D. Cani, R. Bibiloni, C. Knauf et al., "Changes in gut microbiota control metabolic endotoxemia-induced inflammation in high-fat diet-induced obesity and diabetes in mice," Diabetes, vol. 57, no. 6, pp. 1470-1481, 2008.

[38] B. Vandanmagsar, Y. H. Youm, A. Ravussin et al., "The NLRP3 inflammasome instigates obesity-induced inflammation and insulin resistance," Nature Medicine, vol. 17, no. 2, pp. 179-188, 2011.

[39] B. Miraghazadeh and M. C. Cook, "Nuclear factor-kappaB in autoimmunity: man and mouse," Frontiers in Immunology, vol. 9, p. 613, 2018.

[40] S.-X. Tan, K. H. Fisher-Wellman, D. J. Fazakerley et al., "Selective insulin resistance in adipocytes," Journal of Biological Chemistry, vol. 290, no. 18, pp. 11337-11348, 2015.

[41] S. Li, M. S. Brown, and J. L. Goldstein, "Bifurcation of insulin signaling pathway in rat liver: $\mathrm{mTORC1}$ required for stimulation of lipogenesis, but not inhibition of gluconeogenesis," Proceedings of the National Academy of Sciences of the United States of America, vol. 107, no. 8, pp. 3441-3446, 2010.

[42] S. Timmers, M. Nabben, M. Bosma et al., "Augmenting muscle diacylglycerol and triacylglycerol content by blocking fatty acid oxidation does not impede insulin sensitivity," Proceedings of the National Academy of Sciences of the United States of America, vol. 109, no. 29, pp. 11711-11716, 2012.

[43] M. C. Oliveira, Z. Menezes-Garcia, M. C. Henriques et al., "Acute and sustained inflammation and metabolic dysfunction induced by high refined carbohydrate-containing diet in mice," Obesity, vol. 21, no. 9, pp. E396-E406, 2013.

[44] L. S. C. Oliveira, D. A. Santos, S. Barbosa-da-Silva, C. A. Mandarim-de-Lacerda, and M. B. Aguila, "The inflammatory profile and liver damage of a sucrose-rich diet in mice," The Journal of Nutritional Biochemistry, vol. 25, no. 2, pp. 193-200, 2014.

[45] Q. Hao, H. H. Lillefosse, E. Fjaere et al., "High-glycemic index carbohydrates abrogate the antiobesity effect of fish oil in mice," American Journal of Physiology Endocrinology and Metabolism, vol. 302, no. 9, pp. E1097-E1112, 2012.

[46] C. A. Roncal-Jimenez, M. A. Lanaspa, C. J. Rivard et al., "Sucrose induces fatty liver and pancreatic inflammation in male breeder rats independent of excess energy intake," Metabolism, vol. 60, no. 9, pp. 1259-1270, 2011.

[47] W. Wu, H. Tsuchida, T. Kato et al., "Fat and carbohydrate in western diet contribute differently to hepatic lipid accumulation," Biochemical and Biophysical Research Communications, vol. 461, no. 4, pp. 681-686, 2015.

[48] P. C. Calder, N. Ahluwalia, F. Brouns et al., "Dietary factors and low-grade inflammation in relation to overweight and obesity," The British Journal of Nutrition, vol. 106, Supplement 3, pp. S5-78, 2011.

[49] A. Negre-Salvayre, R. Salvayre, N. Augé, R. Pamplona, and M. Portero-Otín, "Hyperglycemia and glycation in diabetic complications," Antioxidants \& Redox Signaling, vol. 11, no. 12, pp. 3071-3109, 2009.

[50] K. Maedler, P. Sergeev, F. Ris et al., "Glucose-induced $\beta$ cell production of IL- $1 \beta$ contributes to glucotoxicity in human pancreatic islets," The Journal of Clinical Investigation, vol. 110, no. 6, pp. 851-860, 2002.

[51] A. J. Wolf, C. N. Reyes, W. Liang et al., "Hexokinase is an innate immune receptor for the detection of bacterial peptidoglycan," Cell, vol. 166, no. 3, pp. 624-636, 2016.

[52] T. Rønningen, A. Shah, A. H. Reiner, P. Collas, and J. Ø. Moskaug, "Epigenetic priming of inflammatory response genes by high glucose in adipose progenitor cells," Biochemical and Biophysical Research Communications, vol. 467, no. 4, pp. 979-986, 2015.

[53] X. Xu, X. Qi, Y. Shao et al., "High glucose inducedmacrophage activation through TGF- $\beta$-activated kinase 1 signaling pathway," Inflammation Research, vol. 65, no. 8, pp. 655-664, 2016.

[54] N. Shanmugam, M. A. Reddy, M. Guha, and R. Natarajan, "High glucose-induced expression of proinflammatory cytokine and chemokine genes in monocytic cells," Diabetes, vol. 52, no. 5, pp. 1256-1264, 2003.

[55] Y. Lin, A. H. Berg, P. Iyengar et al., "The hyperglycemiainduced inflammatory response in adipocytes: the role of reactive oxygen species," Journal of Biological Chemistry, vol. 280, no. 6, pp. 4617-4626, 2005.

[56] Y. Li, H. Ding, X. Wang et al., "High levels of acetoacetate and glucose increase expression of cytokines in bovine hepatocytes, through activation of the NF- $\kappa \mathrm{B}$ signalling pathway," The Journal of Dairy Research, vol. 83, no. 01, pp. 51-57, 2016.

[57] D. Koya, M. R. Jirousek, Y. W. Lin, H. Ishii, K. Kuboki, and G. L. King, "Characterization of protein kinase C beta isoform activation on the gene expression of transforming growth factor-beta, extracellular matrix components, and prostanoids in the glomeruli of diabetic rats," The Journal of Clinical Investigation, vol. 100, no. 1, pp. 115-126, 1997.

[58] V. Kolm-Litty, U. Sauer, A. Nerlich, R. Lehmann, and E. D. Schleicher, "High glucose-induced transforming growth factor betal production is mediated by the hexosamine pathway in porcine glomerular mesangial cells," The Journal of Clinical Investigation, vol. 101, no. 1, pp. 160-169, 1998.

[59] C. J. Green, M. Pedersen, B. K. Pedersen, and C. Scheele, "Elevated NF- $\kappa$ B activation is conserved in human myocytes cultured from obese type 2 diabetic patients and attenuated by AMP-activated protein kinase," Diabetes, vol. 60, no. 11, pp. 2810-2819, 2011.

[60] K. E. Bornfeldt and I. Tabas, "Insulin resistance, hyperglycemia, and atherosclerosis," Cell Metabolism, vol. 14, no. 5, pp. 575-585, 2011.

[61] A. Rimessi, M. Previati, F. Nigro, M. R. Wieckowski, and P. Pinton, "Mitochondrial reactive oxygen species and inflammation: molecular mechanisms, diseases and promising therapies," The International Journal of Biochemistry \& Cell Biology, vol. 81, pp. 281-293, 2016.

[62] R. Zhou, A. Tardivel, B. Thorens, I. Choi, and J. Tschopp, "Thioredoxin-interacting protein links oxidative stress to 
inflammasome activation," Nature Immunology, vol. 11, no. 2, pp. 136-140, 2010.

[63] M. Lamkanfi and V. M. Dixit, "Mechanisms and functions of inflammasomes," Cell, vol. 157, no. 5, pp. 1013-1022, 2014.

[64] Y. Shen, L. Lu, F. Ding et al., "Association of increased serum glycated albumin levels with low coronary collateralization in type 2 diabetic patients with stable angina and chronic total occlusion," Cardiovascular Diabetology, vol. 12, no. 1, p. 165, 2013.

[65] K. Isoda, E. Folco, M. R. Marwali, F. Ohsuzu, and P. Libby, "Glycated LDL increases monocyte CC chemokine receptor 2 expression and monocyte chemoattractant protein-1-mediated chemotaxis," Atherosclerosis, vol. 198, no. 2, pp. 307-312, 2008.

[66] S. F. Yan, R. Ramasamy, and A. M. Schmidt, "Mechanisms of disease: advanced glycation end-products and their receptor in inflammation and diabetes complications," Nature Clinical Practice Endocrinology \& Metabolism, vol. 4, no. 5, pp. 285293, 2008.

[67] B. Liliensiek, M. A. Weigand, A. Bierhaus et al., "Receptor for advanced glycation end products (RAGE) regulates sepsis but not the adaptive immune response," The Journal of Clinical Investigation, vol. 113, no. 11, pp. 1641-1650, 2004.

[68] T. Chavakis, A. Bierhaus, and P. Nawroth, "RAGE (receptor for advanced glycation end products): a central player in the inflammatory response," Microbes and Infection, vol. 6, no. 13, pp. 1219-1225, 2004.

[69] X. Jin, T. Yao, Z.'. Zhou et al., “Advanced glycation end products enhance macrophages polarization into M1 phenotype through activating RAGE/NF- $\kappa \mathrm{B}$ pathway," BioMed Research International, vol. 2015, Article ID 732450, 12 pages, 2015.

[70] T. Chavakis, A. Bierhaus, N. Al-Fakhri et al., "The pattern recognition receptor (RAGE) is a counterreceptor for leukocyte integrins: a novel pathway for inflammatory cell recruitment," The Journal of Experimental Medicine, vol. 198, no. 10, pp. 1507-1515, 2003.

[71] S. C. Lin and D. G. Hardie, "AMPK: sensing glucose as well as cellular energy status," Cell Metabolism, vol. 27, no. 2, pp. 299-313, 2018.

[72] S. Galic, M. D. Fullerton, J. D. Schertzer et al., "Hematopoietic AMPK $\beta 1$ reduces mouse adipose tissue macrophage inflammation and insulin resistance in obesity," The Journal of Clinical Investigation, vol. 121, no. 12, pp. 4903-4915, 2011.

[73] C. R. Lindholm, R. L. Ertel, J. D. Bauwens, E. G. Schmuck, J. D. Mulligan, and K. W. Saupe, "A high-fat diet decreases AMPK activity in multiple tissues in the absence of hyperglycemia or systemic inflammation in rats," Journal of Physiology and Biochemistry, vol. 69, no. 2, pp. 165-175, 2013.

[74] D. Sag, D. Carling, R. D. Stout, and J. Suttles, “Adenosine $5^{\prime}$-monophosphate-activated protein kinase promotes macrophage polarization to an anti-inflammatory functional phenotype," Journal of Immunology, vol. 181, no. 12, pp. 8633-8641, 2008.

[75] C. M. Krawczyk, T. Holowka, J. Sun et al., "Toll-like receptorinduced changes in glycolytic metabolism regulate dendritic cell activation," Blood, vol. 115, no. 23, pp. 4742-4749, 2010.

[76] G. Pilon, P. Dallaire, and A. Marette, "Inhibition of inducible nitric-oxide synthase by activators of AMP-activated protein kinase: a new mechanism of action of insulin-sensitizing drugs," Journal of Biological Chemistry, vol. 279, no. 20, pp. 20767-20774, 2004.
[77] X. Zhao, J. W. Zmijewski, E. Lorne et al., "Activation of AMPK attenuates neutrophil proinflammatory activity and decreases the severity of acute lung injury," American Journal of Physiology-Lung Cellular and Molecular Physiology, vol. 295, no. 3, pp. L497-L504, 2008.

[78] S. A. Hawley, M. D. Fullerton, F. A. Ross et al., "The ancient drug salicylate directly activates AMP-activated protein kinase," Science, vol. 336, no. 6083, pp. 918-922, 2012.

[79] T. Kadowaki, T. Yamauchi, N. Kubota, K. Hara, K. Ueki, and $\mathrm{K}$. Tobe, "Adiponectin and adiponectin receptors in insulin resistance, diabetes, and the metabolic syndrome," The Journal of Clinical Investigation, vol. 116, no. 7, pp. 1784-1792, 2006.

[80] P. Felig, E. Marliss, and G. F. Cahill Jr, "Plasma amino acid levels and insulin secretion in obesity," The New England Journal of Medicine, vol. 281, no. 15, pp. 811-816, 1969.

[81] C. B. Newgard, J. An, J. R. Bain et al., "A branched-chain amino acid-related metabolic signature that differentiates obese and lean humans and contributes to insulin resistance," Cell Metabolism, vol. 9, no. 4, pp. 311-326, 2009.

[82] T. J. Wang, M. G. Larson, R. S. Vasan et al., "Metabolite profiles and the risk of developing diabetes," Nature Medicine, vol. 17, no. 4, pp. 448-453, 2011.

[83] C. J. Lynch and S. H. Adams, "Branched-chain amino acids in metabolic signalling and insulin resistance," Nature Reviews Endocrinology, vol. 10, no. 12, pp. 723-736, 2014.

[84] C. B. Newgard, "Interplay between lipids and branched-chain amino acids in development of insulin resistance," Cell Metabolism, vol. 15, no. 5, pp. 606-614, 2012.

[85] F. Tremblay, M. Krebs, L. Dombrowski et al., "Overactivation of S6 kinase 1 as a cause of human insulin resistance during increased amino acid availability," Diabetes, vol. 54, no. 9, pp. 2674-2684, 2005.

[86] F. Tremblay and A. Marette, "Amino acid and insulin signaling via the mTOR/p 70 S6 kinase pathway. A negative feedback mechanism leading to insulin resistance in skeletal muscle cells," Journal of Biological Chemistry, vol. 276, no. 41, pp. 38052-38060, 2001.

[87] S. H. Um, F. Frigerio, M. Watanabe et al., "Absence of S6K1 protects against age- and diet-induced obesity while enhancing insulin sensitivity," Nature, vol. 431, no. 7005, pp. 200 205, 2004.

[88] L. Khamzina, A. Veilleux, S. Bergeron, and A. Marette, "Increased activation of the mammalian target of rapamycin pathway in liver and skeletal muscle of obese rats: possible involvement in obesity-linked insulin resistance," Endocrinology, vol. 146, no. 3, pp. 1473-1481, 2005.

[89] U. Ozcan, E. Yilmaz, L. Ozcan et al., "Chemical chaperones reduce ER stress and restore glucose homeostasis in a mouse model of type 2 diabetes," Science, vol. 313, no. 5790, pp. 1137-1140, 2006.

[90] F. Urano, X. Wang, A. Bertolotti et al., "Coupling of stress in the ER to activation of JNK protein kinases by transmembrane protein kinase IRE1," Science, vol. 287, no. 5453, pp. 664-666, 2000.

[91] J. S. Burrill, E. K. Long, B. Reilly et al., "Inflammation and ER stress regulate branched-chain amino acid uptake and metabolism in adipocytes," Molecular Endocrinology, vol. 29, no. 3, pp. 411-420, 2015.

[92] A. Jennings, A. MacGregor, T. Pallister, T. Spector, and A. Cassidy, "Associations between branched chain amino 
acid intake and biomarkers of adiposity and cardiometabolic health independent of genetic factors: a twin study," International Journal of Cardiology, vol. 223, pp. 992-998, 2016.

[93] Y. Zhang, K. Guo, R. E. LeBlanc, D. Loh, G. J. Schwartz, and $\mathrm{Y} . \mathrm{H}$. Yu, "Increasing dietary leucine intake reduces diet-induced obesity and improves glucose and cholesterol metabolism in mice via multimechanisms," Diabetes, vol. 56, no. 6, pp. 1647-1654, 2007.

[94] H. G. Shertzer, S. E. Woods, M. Krishan, M. B. Genter, and K. J. Pearson, "Dietary whey protein lowers the risk for metabolic disease in mice fed a high-fat diet," The Journal of Nutrition, vol. 141, no. 4, pp. 582-587, 2011.

[95] T. Li, L. Geng, X. Chen, M. Miskowiec, X. Li, and B. Dong, "Branched-chain amino acids alleviate nonalcoholic steatohepatitis in rats," Applied Physiology, Nutrition, and Metabolism, vol. 38, no. 8, pp. 836-843, 2013.

[96] K. Tajiri and Y. Shimizu, "Branched-chain amino acids in liver diseases," World Journal of Gastroenterology, vol. 19, no. 43, pp. 7620-7629, 2013.

[97] D. Terakura, M. Shimizu, J. Iwasa et al., "Preventive effects of branched-chain amino acid supplementation on the spontaneous development of hepatic preneoplastic lesions in C57BL/KsJ-db/db obese mice," Carcinogenesis, vol. 33, no. 12, pp. 2499-2506, 2012.

[98] C. H. Lang, C. J. Lynch, and T. C. Vary, "BCATm deficiency ameliorates endotoxin-induced decrease in muscle protein synthesis and improves survival in septic mice," American Journal of Physiology-Regulatory, Integrative and Comparative Physiology, vol. 299, no. 3, pp. R935-R944, 2010.

[99] R. L. Wolfson, L. Chantranupong, R. A. Saxton et al., "Sestrin 2 is a leucine sensor for the mTORC1 pathway," Science, vol. 351, no. 6268, pp. 43-48, 2016.

[100] D. F. Lee, H. P. Kuo, C. T. Chen et al., "IKK $\beta$ suppression of TSC1 links inflammation and tumor angiogenesis via the mTOR pathway," Cell, vol. 130, no. 3, pp. 440-455, 2007.

[101] D. F. Lee, H. P. Kuo, C. T. Chen et al., "IKK $\beta$ suppression of TSC1 function links the mTOR pathway with insulin resistance," International Journal of Molecular Medicine, vol. 22, no. 5, pp. 633-638, 2008.

[102] M. Martin, R. E. Schifferle, N. Cuesta, S. N. Vogel, J. Katz, and S. M. Michalek, "Role of the phosphatidylinositol 3 kinase-Akt pathway in the regulation of IL-10 and IL-12 by Porphyromonas gingivalis lipopolysaccharide," Journal of Immunology, vol. 171, no. 2, pp. 717-725, 2003.

[103] W. T. Festuccia, P. Pouliot, I. Bakan, D. M. Sabatini, and M. Laplante, "Myeloid-specific Rictor deletion induces M1 macrophage polarization and potentiates in vivo proinflammatory response to lipopolysaccharide," PLoS One, vol. 9, no. 4, article e95432, 2014.

[104] V. A. Paschoal, M. T. Amano, T. Belchior et al., "mTORC1 inhibition with rapamycin exacerbates adipose tissue inflammation in obese mice and dissociates macrophage phenotype from function," Immunobiology, vol. 222, no. 2, pp. 261-271, 2017.

[105] K. Makki, S. Taront, O. Molendi-Coste et al., "Beneficial metabolic effects of rapamycin are associated with enhanced regulatory cells in diet-induced obese mice," PLoS One, vol. 9, no. 4, article e92684, 2014.

[106] A. Mercalli, I. Calavita, E. Dugnani et al., "Rapamycin unbalances the polarization of human macrophages to M1," Immunology, vol. 140, no. 2, pp. 179-190, 2013.
[107] T. Weichhart, G. Costantino, M. Poglitsch et al., "The TSCmTOR signaling pathway regulates the innate inflammatory response," Immunity, vol. 29, no. 4, pp. 565-577, 2008.

[108] H. Jiang, M. Westerterp, C. Wang, Y. Zhu, and D. Ai, "Macrophage mTORC1 disruption reduces inflammation and insulin resistance in obese mice," Diabetologia, vol. 57, no. 11, pp. 2393-2404, 2014.

[109] P. Chimin, M. L. Andrade, T. Belchior et al., "Adipocyte mTORC1 deficiency promotes adipose tissue inflammation and NLRP3 inflammasome activation via oxidative stress and de novo ceramide synthesis," Journal of Lipid Research, vol. 58, no. 9, pp. 1797-1807, 2017.

[110] M. Linke, H. T. T. Pham, K. Katholnig et al., "Chronic signaling via the metabolic checkpoint kinase mTORC1 induces macrophage granuloma formation and marks sarcoidosis progression," Nature Immunology, vol. 18, no. 3, pp. 293302, 2017.

[111] H. Pan, X. P. Zhong, and S. Lee, "Sustained activation of mTORC1 in macrophages increases AMPK $\alpha$-dependent autophagy to maintain cellular homeostasis," BMC Biochemistry, vol. 17, no. 1, p. 14, 2016.

[112] A. J. Covarrubias, H. I. Aksoylar, J. Yu et al., “Akt-mTORC1 signaling regulates Acly to integrate metabolic input to control of macrophage activation," eLife, vol. 5, article e11612, 2016.

[113] H. Pan, T. F. O'Brien, P. Zhang, and X. P. Zhong, "The role of tuberous sclerosis complex 1 in regulating innate immunity," Journal of Immunology, vol. 188, no. 8, pp. 3658-3666, 2012.

[114] V. Byles, A. J. Covarrubias, I. Ben-Sahra et al., "The TSCmTOR pathway regulates macrophage polarization," Nature Communications, vol. 4, no. 1, p. 2834, 2013.

[115] C. Fang, J. Yu, Y. Luo et al., "Tsc 1 is a critical regulator of macrophage survival and function," Cellular Physiology and Biochemistry, vol. 36, no. 4, pp. 1406-1418, 2015.

[116] T. Weichhart, M. Hengstschläger, and M. Linke, "Regulation of innate immune cell function by mTOR," Nature Reviews Immunology, vol. 15, no. 10, pp. 599-614, 2015.

[117] J. D. Powell, K. N. Pollizzi, E. B. Heikamp, and M. R. Horton, "Regulation of immune responses by mTOR," Annual Review of Immunology, vol. 30, no. 1, pp. 39-68, 2012.

[118] J. Brown, H. Wang, J. Suttles, D. T. Graves, and M. Martin, "Mammalian target of rapamycin complex 2 (mTORC2) negatively regulates Toll-like receptor 4-mediated inflammatory response via FoxO1," Journal of Biological Chemistry, vol. 286, no. 52, pp. 44295-44305, 2011.

[119] S. C.-C. Huang, A. M. Smith, B. Everts et al., "Metabolic reprogramming mediated by the mTORC2-IRF4 signaling axis is essential for macrophage alternative activation," Immunity, vol. 45, no. 4, pp. 817-830, 2016.

[120] A. M. Kirwan, Y. M. Lenighan, M. E. O'Reilly, F. C. McGillicuddy, and H. M. Roche, "Nutritional modulation of metabolic inflammation," Biochemical Society Transactions, vol. 45, no. 4, pp. 979-985, 2017.

[121] M. B. Fessler, L. L. Rudel, and J. M. Brown, "Toll-like receptor signaling links dietary fatty acids to the metabolic syndrome," Current Opinion in Lipidology, vol. 20, no. 5, pp. 379-385, 2009.

[122] E. Patterson, R. Wall, G. F. Fitzgerald, R. P. Ross, and C. Stanton, "Health implications of high dietary omega-6 polyunsaturated fatty acids," Journal of Nutrition and Metabolism, vol. 2012, Article ID 539426, 16 pages, 2012. 
[123] M. B. MacLennan, S. E. Clarke, K. Perez et al., "Mammary tumor development is directly inhibited by lifelong $\mathrm{n}-3$ polyunsaturated fatty acids," The Journal of Nutritional Biochemistry, vol. 24, no. 1, pp. 388-395, 2013.

[124] J. Tan, C. McKenzie, M. Potamitis, A. N. Thorburn, C. R. Mackay, and L. Macia, "The role of short-chain fatty acids in health and disease," Advances in Immunology, vol. 121, pp. 91-119, 2014.

[125] S. Hammad, S. Pu, and P. J. Jones, "Current evidence supporting the link between dietary fatty acids and cardiovascular disease," Lipids, vol. 51, no. 5, pp. 507-517, 2016.

[126] Central Committee for Medical and Community Program of the American Heart Association, "Dietary fat and its relation to heart attacks and strokes," JAMA, vol. 175, no. 5, pp. 389391, 1961.

[127] A. M. Murphy, C. L. Lyons, O. M. Finucane, and H. M. Roche, "Interactions between differential fatty acids and inflammatory stressors-impact on metabolic health," Prostaglandins, Leukotrienes, and Essential Fatty Acids, vol. 92, pp. 49-55, 2015.

[128] J. Y. Lee, K. H. Sohn, S. H. Rhee, and D. Hwang, "Saturated fatty acids, but not unsaturated fatty acids, induce the expression of cyclooxygenase-2 mediated through Toll-like receptor 4," Journal of Biological Chemistry, vol. 276, no. 20, pp. 16683-16689, 2001.

[129] H. Wen, D. Gris, Y. Lei et al., "Fatty acid-induced NLRP3ASC inflammasome activation interferes with insulin signaling," Nature Immunology, vol. 12, no. 5, pp. 408-415, 2011.

[130] D. Wang, Y. Wei, and M. J. Pagliassotti, "Saturated fatty acids promote endoplasmic reticulum stress and liver injury in rats with hepatic steatosis," Endocrinology, vol. 147, no. 2, pp. 943-951, 2006.

[131] W. L. Holland, B. T. Bikman, L. P. Wang et al., "Lipidinduced insulin resistance mediated by the proinflammatory receptor TLR4 requires saturated fatty acid-induced ceramide biosynthesis in mice," The Journal of Clinical Investigation, vol. 121, no. 5, pp. 1858-1870, 2011.

[132] S. Crunkhorn, F. Dearie, C. Mantzoros et al., "Peroxisome proliferator activator receptor gamma coactivator-1 expression is reduced in obesity: potential pathogenic role of saturated fatty acids and p 38 mitogen-activated protein kinase activation," Journal of Biological Chemistry, vol. 282, no. 21, pp. 15439-15450, 2007.

[133] H. Shi, M. V. Kokoeva, K. Inouye, I. Tzameli, H. Yin, and J. S. Flier, "TLR4 links innate immunity and fatty acid-induced insulin resistance," The Journal of Clinical Investigation, vol. 116, no. 11, pp. 3015-3025, 2006.

[134] Y. Watanabe, Y. Nagai, and K. Takatsu, "Activation and regulation of the pattern recognition receptors in obesityinduced adipose tissue inflammation and insulin resistance," Nutrients, vol. 5, no. 9, pp. 3757-3778, 2013.

[135] D. M. Erion and G. I. Shulman, "Diacylglycerol-mediated insulin resistance," Nature Medicine, vol. 16, no. 4, pp. 400402, 2010.

[136] C. E. Chalfant, K. Kishikawa, M. C. Mumby, C. Kamibayashi, A. Bielawska, and Y. A. Hannun, "Long chain ceramides activate protein phosphatase-1 and protein phosphatase-2A. Activation is stereospecific and regulated by phosphatidic acid," Journal of Biological Chemistry, vol. 274, no. 29, pp. 20313-20317, 1999.
[137] D. J. Powell, E. Hajduch, G. Kular, and H. S. Hundal, "Ceramide disables 3-phosphoinositide binding to the pleckstrin homology domain of protein kinase B (PKB)/Akt by a PKC $\zeta$-dependent mechanism," Molecular and Cellular Biology, vol. 23, no. 21, pp. 7794-7808, 2003.

[138] C. Lipina and H. S. Hundal, "Sphingolipids: agents provocateurs in the pathogenesis of insulin resistance," Diabetologia, vol. 54, no. 7, pp. 1596-1607, 2011.

[139] G. H. Norris and C. N. Blesso, "Dietary and endogenous sphingolipid metabolism in chronic inflammation," Nutrients, vol. 9, no. 11, 2017.

[140] O. M. Finucane, C. L. Lyons, A. M. Murphy et al., "Monounsaturated fatty acid-enriched high-fat diets impede adipose NLRP3 inflammasome-mediated IL- $1 \beta$ secretion and insulin resistance despite obesity," Diabetes, vol. 64, no. 6, pp. 21162128, 2015.

[141] C. L. Lyons, E. B. Kennedy, and H. M. Roche, "Metabolic inflammation-differential modulation by dietary constituents," Nutrients, vol. 8, no. 5, p. 247, 2016.

[142] J. Shirakawa, H. Fujii, K. Ohnuma et al., "Diet-induced adipose tissue inflammation and liver steatosis are prevented by DPP-4 inhibition in diabetic mice," Diabetes, vol. 60, no. 4, pp. 1246-1257, 2011.

[143] N. Granados, J. Amengual, J. Ribot, A. Palou, and M. L. Bonet, "Distinct effects of oleic acid and its trans-isomer elaidic acid on the expression of myokines and adipokines in cell models," The British Journal of Nutrition, vol. 105, no. 08, pp. 1226-1234, 2011.

[144] L. S. Maguire, S. M. O'Sullivan, K. Galvin, T. P. O'Connor, and N. M. O'Brien, "Fatty acid profile, tocopherol, squalene and phytosterol content of walnuts, almonds, peanuts, hazelnuts and the macadamia nut," International Journal of Food Sciences and Nutrition, vol. 55, no. 3, pp. 171-178, 2004.

[145] E. A. Lima, L. S. Silveira, L. N. Masi et al., "Macadamia oil supplementation attenuates inflammation and adipocyte hypertrophy in obese mice," Mediators of Inflammation, vol. 2014, Article ID 870634, 9 pages, 2014.

[146] H. Cao, K. Gerhold, J. R. Mayers, M. M. Wiest, S. M. Watkins, and G. S. Hotamisligil, "Identification of a lipokine, a lipid hormone linking adipose tissue to systemic metabolism," Cell, vol. 134, no. 6, pp. 933-944, 2008.

[147] Z. H. Yang, H. Miyahara, and A. Hatanaka, "Chronic administration of palmitoleic acid reduces insulin resistance and hepatic lipid accumulation in KK-Ay mice with genetic type 2 diabetes," Lipids in Health and Disease, vol. 10, no. 1, p. 120, 2011.

[148] E. Diakogiannaki, S. Dhayal, C. E. Childs, P. C. Calder, H. J. Welters, and N. G. Morgan, "Mechanisms involved in the cytotoxic and cytoprotective actions of saturated versus monounsaturated long-chain fatty acids in pancreatic $\beta$ cells," The Journal of Endocrinology, vol. 194, no. 2, pp. 283-291, 2007.

[149] N. G. Morgan and S. Dhayal, "Unsaturated fatty acids as cytoprotective agents in the pancreatic $\beta$-cell," Prostaglandins, Leukotrienes, and Essential Fatty Acids, vol. 82, no. 46, pp. 231-236, 2010.

[150] C. O. Souza, A. A. S. Teixeira, E. A. Lima et al., "Palmitoleic acid (n-7) attenuates the immunometabolic disturbances caused by a high-fat diet independently of PPAR $\alpha$," Mediators of Inflammation, vol. 2014, Article ID 582197, 12 pages, 2014. 
[151] C. O. de Souza, A. A. S. Teixeira, L. A. Biondo, E. A. Lima Junior, H. A. P. Batatinha, and J. C. Rosa Neto, "Palmitoleic acid improves metabolic functions in fatty liver by PPAR $\alpha$ dependent AMPK activation," Journal of Cellular Physiology, vol. 232, no. 8, pp. 2168-2177, 2017.

[152] C. O. Souza, A. A. Teixeira, L. A. Biondo, L. S. Silveira, P. C. Calder, and J. C. Rosa Neto, "Palmitoleic acid reduces the inflammation in LPS-stimulated macrophages by inhibition of NF $\kappa \mathrm{B}$, independently of PPARs," Clinical and Experimental Pharmacology \& Physiology, vol. 44, no. 5, pp. 566-575, 2017.

[153] I. Çimen, B. Kocatürk, S. Koyuncu et al., "Prevention of atherosclerosis by bioactive palmitoleate through suppression of organelle stress and inflammasome activation," Science Translational Medicine, vol. 8, no. 358, article 358ra126, 2016.

[154] K. L. Chan, N. J. Pillon, D. M. Sivaloganathan et al., "Palmitoleate reverses high fat-induced proinflammatory macrophage polarization via AMP-activated protein kinase (AMPK)," Journal of Biological Chemistry, vol. 290, no. 27, pp. 16979-16988, 2015.

[155] C. O. de Souza, G. K. Vannice, J. C. Rosa Neto, and P. C. Calder, "Is palmitoleic acid a plausible nonpharmacological strategy to prevent or control chronic metabolic and inflammatory disorders?," Molecular Nutrition \& Food Research, vol. 62, no. 1, 2018.

[156] A. Bolsoni-Lopes, W. T. Festuccia, T. S. M. Farias et al., "Palmitoleic acid (n-7) increases white adipocyte lipolysis and lipase content in a PPAR $\alpha$-dependent manner," American Journal of Physiology-Endocrinology and Metabolism, vol. 305, no. 9, pp. E1093-E1102, 2013.

[157] A. Bolsoni-Lopes, W. T. Festuccia, P. Chimin et al., "Palmitoleic acid (n-7) increases white adipocytes GLUT4 content and glucose uptake in association with AMPK activation," Lipids in Health and Disease, vol. 13, no. 1, p. 199, 2014.

[158] A. P. Simopoulos, "Evolutionary aspects of diet, the omega-6/ omega-3 ratio and genetic variation: nutritional implications for chronic diseases," Biomedicine \& Pharmacotherapy, vol. 60, no. 9, pp. 502-507, 2006.

[159] A. P. Simopoulos, "An increase in the omega-6/omega-3 fatty acid ratio increases the risk for obesity," Nutrients, vol. 8, no. 3, p. 128, 2016.

[160] R. P. Mensink and M. B. Katan, "Effect of dietary fatty acids on serum lipids and lipoproteins. A meta- analysis of 27 trials," Arteriosclerosis and Thrombosis, vol. 12, no. 8, pp. 911-919, 1992.

[161] B. Hennig, M. Toborek, S. Joshi-Barve et al., "Linoleic acid activates nuclear transcription factor $-\kappa \mathrm{B}(\mathrm{NF}-\kappa \mathrm{B})$ and induces NF- $\kappa$ B-dependent transcription in cultured endothelial cells," The American Journal of Clinical Nutrition, vol. 63, no. 3, pp. 322-328, 1996.

[162] P. C. Calder, "Functional roles of fatty acids and their effects on human health," JPEN Journal of Parenteral and Enteral Nutrition, vol. 39, pp. 18S-32S, 2015.

[163] P. Li, D. Y. Oh, G. Bandyopadhyay et al., "LTB4 promotes insulin resistance in obese mice by acting on macrophages, hepatocytes and myocytes," Nature Medicine, vol. 21, no. 3, pp. 239-247, 2015.

[164] E. Börgeson, A. M. F. Johnson, Y. S. Lee et al., "Lipoxin A4 attenuates obesity-induced adipose inflammation and associated liver and kidney disease," Cell Metabolism, vol. 22, no. 1, pp. 125-137, 2015.
[165] T. A. B. Sanders, M. Vickers, and A. P. Haines, "Effect on blood lipids and haemostasis of a supplement of cod-liver oil, rich in eicosapentaenoic and docosahexaenoic acids, in healthy young men," Clinical Science, vol. 61, no. 3, pp. 317-324, 1981.

[166] A. A. Ahmed and B. J. Holub, "Alteration and recovery of bleeding times, platelet aggregation and fatty acid composition of individual phospholipids in platelets of human subjects receiving a supplement of cod-liver oil," Lipids, vol. 19, no. 8, pp. 617-624, 1984.

[167] H. R. Knapp, I. A. G. Reilly, P. Alessandrini, and G. A. FitzGerald, "In vivo indexes of platelet and vascular function during fish-oil administration in patients with atherosclerosis," The New England Journal of Medicine, vol. 314, no. 15, pp. 937-942, 1986.

[168] J. M. Kremer, W. Jubiz, A. Michalek et al., "Fish-oil fatty acid supplementation in active rheumatoid arthritis. A doubleblinded, controlled, crossover study," Annals of Internal Medicine, vol. 106, no. 4, pp. 497-503, 1987.

[169] A. Bjørneboe, E. Søyland, G.-E. A. Bjørneboe, G. Rajka, and C. A. Drevon, "Effect of dietary supplementation with eicosapentaenoic acid in the treatment of atopic dermatitis," The British Journal of Dermatology, vol. 117, no. 4, pp. 463-469, 1987.

[170] J. Li, F. R. Li, D. Wei et al., "Endogenous $\omega-3$ polyunsaturated fatty acid production confers resistance to obesity, dyslipidemia, and diabetes in mice," Molecular Endocrinology, vol. 28, no. 8, pp. 1316-1328, 2014.

[171] D. Y. Oh, S. Talukdar, E. J. Bae et al., "GPR120 is an omega-3 fatty acid receptor mediating potent anti-inflammatory and insulin-sensitizing effects," Cell, vol. 142, no. 5, pp. 687-698, 2010.

[172] T. Belchior, V. A. Paschoal, J. Magdalon et al., "Omega-3 fatty acids protect from diet-induced obesity, glucose intolerance, and adipose tissue inflammation through PPAR $\gamma$-dependent and PPAR $\gamma$-independent actions," Molecular Nutrition \& Food Research, vol. 59, no. 5, pp. 957-967, 2015.

[173] E. A. F. Herbst, S. Paglialunga, C. Gerling et al., "Omega-3 supplementation alters mitochondrial membrane composition and respiration kinetics in human skeletal muscle," The Journal of Physiology, vol. 592, no. 6, pp. 1341-1352, 2014.

[174] C. N. Serhan, "Pro-resolving lipid mediators are leads for resolution physiology," Nature, vol. 510, no. 7503, pp. 92-101, 2014.

[175] M. Bjursell, X. Xu, T. Admyre et al., "The beneficial effects of n-3 polyunsaturated fatty acids on diet induced obesity and impaired glucose control do not require Gpr 120," PLoS One, vol. 9, no. 12, article e114942, 2014.

[176] S. I. Pærregaard, M. Agerholm, A. K. Serup et al., "FFAR4 (GPR120) signaling is not required for anti-inflammatory and insulin-sensitizing effects of omega-3 fatty acids," Mediators of Inflammation, vol. 2016, Article ID 1536047, 12 pages, 2016.

[177] C. N. Serhan, "Resolution phase of inflammation: novel endogenous anti-inflammatory and proresolving lipid mediators and pathways," Annual Review of Immunology, vol. 25, pp. 101-137, 2007.

[178] A. González-Périz, R. Horrillo, N. Ferré et al., "Obesityinduced insulin resistance and hepatic steatosis are alleviated by omega- 3 fatty acids: a role for resolvins and protectins," The FASEB Journal, vol. 23, no. 6, pp. 1946-1957, 2009. 
[179] J. Hellmann, Y. Tang, M. Kosuri, A. Bhatnagar, and M. Spite, "Resolvin D1 decreases adipose tissue macrophage accumulation and improves insulin sensitivity in obese-diabetic mice," The FASEB Journal, vol. 25, no. 7, pp. 2399-2407, 2011.

[180] P. J. White, P. St-Pierre, A. Charbonneau et al., "Protectin DX alleviates insulin resistance by activating a myokine-liver glucoregulatory axis," Nature Medicine, vol. 20, no. 6, pp. 664669, 2014.

[181] N. I. McNeil, "The contribution of the large intestine to energy supplies in man," The American Journal of Clinical Nutrition, vol. 39, no. 2, pp. 338-342, 1984.

[182] G. den Besten, A. Bleeker, A. Gerding et al., "Short-chain fatty acids protect against high-fat diet-induced obesity via a PPAR $\gamma$-dependent switch from lipogenesis to fat oxidation," Diabetes, vol. 64, no. 7, pp. 2398-2408, 2015.

[183] V. Andrade-Oliveira, M. T. Amano, M. Correa-Costa et al., "Gut bacteria products prevent AKI induced by ischemiareperfusion," JASN Journal of the American Society of Nephrology, vol. 26, no. 8, pp. 1877-1888, 2015.

[184] X. Wang, G. He, Y. Peng, W. Zhong, Y. Wang, and B. Zhang, "Sodium butyrate alleviates adipocyte inflammation by inhibiting NLRP3 pathway," Scientific Reports, vol. 5, no. 1, article 12676, 2015.

[185] S.'a. al-Lahham, H. Roelofsen, F. Rezaee et al., "Propionic acid affects immune status and metabolism in adipose tissue from overweight subjects," European Journal of Clinical Investigation, vol. 42, no. 4, pp. 357-364, 2012.

[186] P. M. Smith, M. R. Howitt, N. Panikov et al., "The microbial metabolites, short-chain fatty acids, regulate colonic Treg cell homeostasis," Science, vol. 341, no. 6145, pp. 569-573, 2013.

[187] H. Ohira, W. Tsutsui, and Y. Fujioka, "Are short chain fatty acids in gut microbiota defensive players for inflammation and atherosclerosis?," Journal of Atherosclerosis and Thrombosis, vol. 24, no. 7, pp. 660-672, 2017.

[188] Z. Ang and J. L. Ding, "GPR41 and GPR43 in obesity and inflammation - protective or causative?," Frontiers in Immunology, vol. 7, p. 28, 2016.

[189] T. Liu, J. Li, Y. Liu et al., "Short-chain fatty acids suppress lipopolysaccharide-induced production of nitric oxide and proinflammatory cytokines through inhibition of NF- $\kappa \mathrm{B}$ pathway in RAW264.7 cells," Inflammation, vol. 35, no. 5, pp. 1676-1684, 2012.

[190] M. Sahuri-Arisoylu, L. P. Brody, J. R. Parkinson et al., "Reprogramming of hepatic fat accumulation and 'browning' of adipose tissue by the short-chain fatty acid acetate," International Journal of Obesity, vol. 40, no. 6, pp. 955-963, 2016.

[191] W. E. Gall, K. Beebe, K. A. Lawton et al., “ $\alpha$-Hydroxybutyrate is an early biomarker of insulin resistance and glucose intolerance in a nondiabetic population," PLoS One, vol. 5, no. 5, article e10883, 2010.

[192] M. M. Yore, I. Syed, P. M. Moraes-Vieira et al., "Discovery of a class of endogenous mammalian lipids with anti-diabetic and anti-inflammatory effects," Cell, vol. 159, no. 2, pp. 318-332, 2014. 


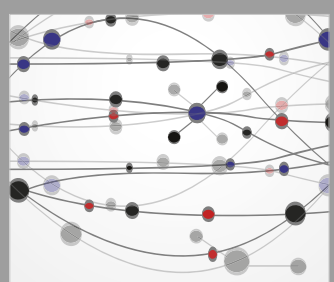

The Scientific World Journal
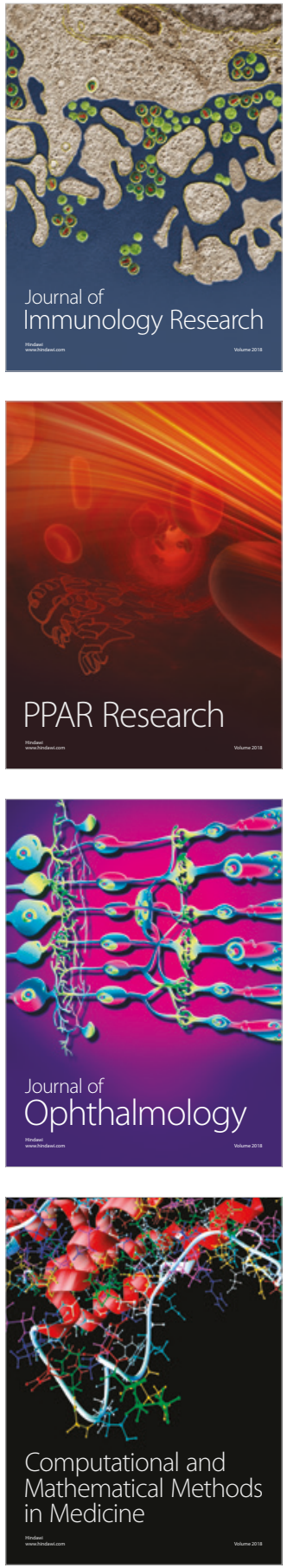

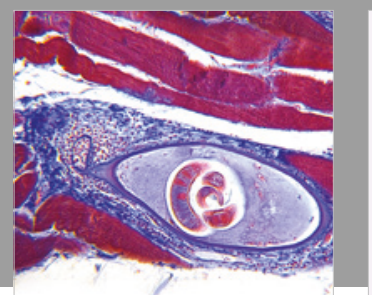

Gastroenterology Research and Practice

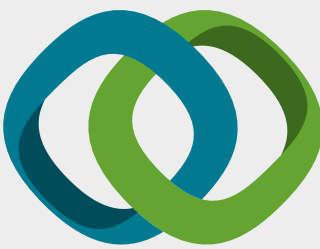

\section{Hindawi}

Submit your manuscripts at

www.hindawi.com
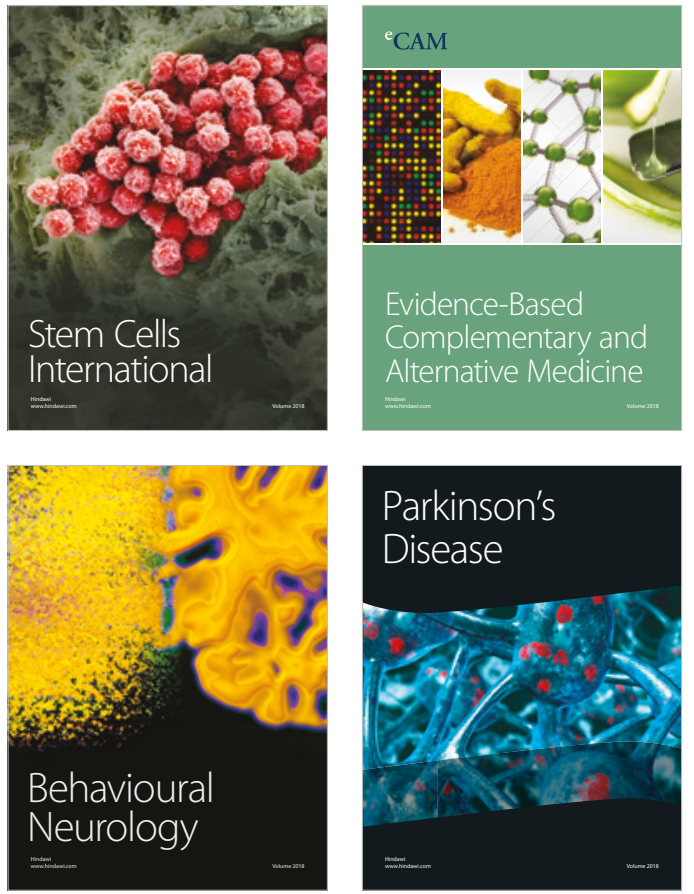

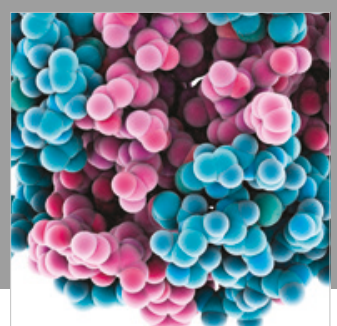

ournal of

Diabetes Research

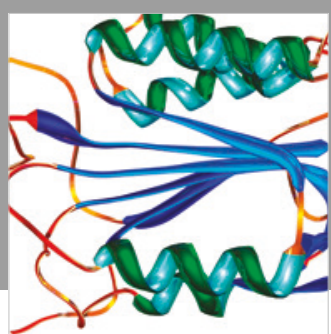

Disease Markers
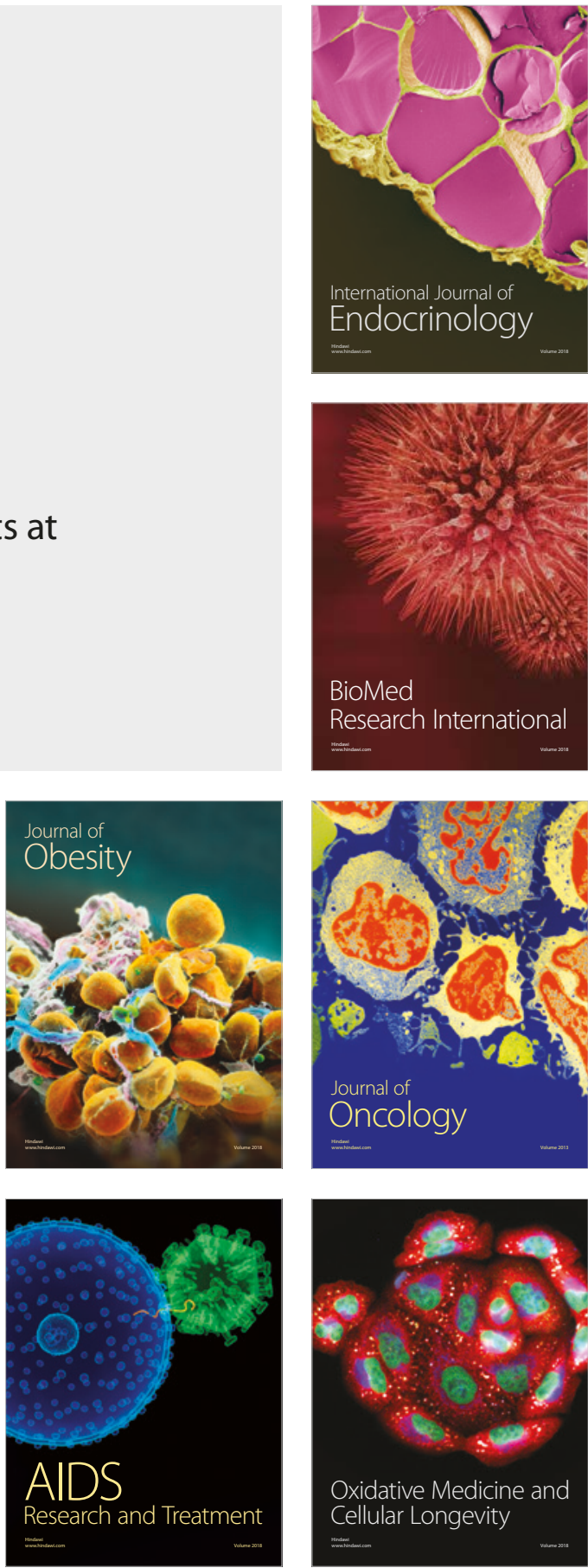